Supporting Information for

\title{
Application of Povarov Reaction in Biaryls under Iron Catalysis for the General Synthesis of Dibenzo[a,c]acridines
}

\author{
Baitan Chakraborty, Abhishek Kar, Rupsa Chanda, Umasish Jana* \\ Department of Chemistry, Jadavpur University, Kolkata 700032, West Bengal, India \\ E-mail: jumasish2004@yahoo.co.in, umasish@gmail.com.
}

\section{Content}

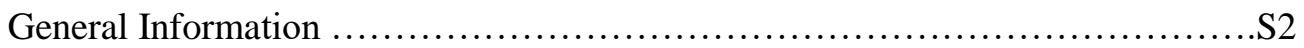

General Experimental Procedure for the syntheses of the compounds 3 ...........S2

Experimental Procedure for the 2 mmol-scale synthesis of the compound 3aa.......S2

Experimental procedure for the synthesis of the compound $\mathbf{5 f a} \ldots \ldots \ldots \ldots \ldots \ldots . . . .52$

Absorption and Emission spectra of the studied compounds......................S4

Figure S1. ORTEP diagram of the crystal structure of $\mathbf{3 a d} \ldots \ldots \ldots \ldots \ldots \ldots \ldots . . \ldots \ldots 11$

Methods for the Sample Preparation and Crystal Measurements for the X-ray

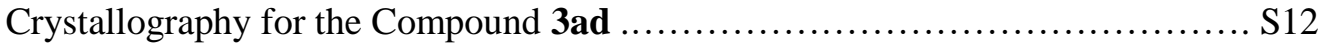

Table S1. Crystallographic data and structural refinement parameters for 3ad..... S12

${ }^{1} \mathrm{H}$ NMR and ${ }^{13} \mathrm{C}$ NMR spectra.............................................. 13 
General Information: ${ }^{1} \mathrm{H}$ NMR spectra were recorded with a $400 \mathrm{MHz}$ spectrometer as solutions in $\mathrm{CDCl}_{3}$. Chemical shifts are expressed in parts per million (ppm, $\delta$ ) and are referenced to $\mathrm{CDCl}_{3}(\delta 7.26 \mathrm{ppm}$ for all of the compounds) as an internal standard. All coupling constants are absolute values and are expressed in Hz. The description of the signals include the following: $\mathrm{s}=$ singlet, $\mathrm{d}=$ doublet, $\mathrm{dd}=$ doublet of doublets, $\mathrm{ddd}=$ doublet of doublets of doublets, $\mathrm{t}=$ triplet, $\mathrm{q}=$ quartet, $\mathrm{m}=$ multiplet and $\mathrm{td}=$ triplet of doublets. ${ }^{13} \mathrm{C}$ NMR spectra were recorded with 400 (75) $\mathrm{MHz}$ spectrometers as solutions in $\mathrm{CDCl}_{3}$ with complete proton decoupling. Chemical shifts are expressed in parts per million (ppm, $\delta)$ and are referenced to $\mathrm{CHCl}_{3}(\delta=77.0 \mathrm{ppm})$ as an internal standard. Electrospray ionization technique and TOF mass analyzer were used for HRMS. Single-crystal X-ray data was recorded in a diffractometer with Mo K $\alpha$ radiation. The routine monitoring of the reaction was performed with silica gel coated aluminium sheet TLC (Merck). Solvents, reagents, and chemicals were purchased from Aldrich, Alfa aeser, Merck, SRL, Spectrochem. All reactions involving moisture-sensitive reactants were executed with oven-dried glassware. Reactions that required heating were performed in silicon oil bath.

\section{General experimental procedure for the synthesis of dibenzo[a,c]acridine derivatives (3)}

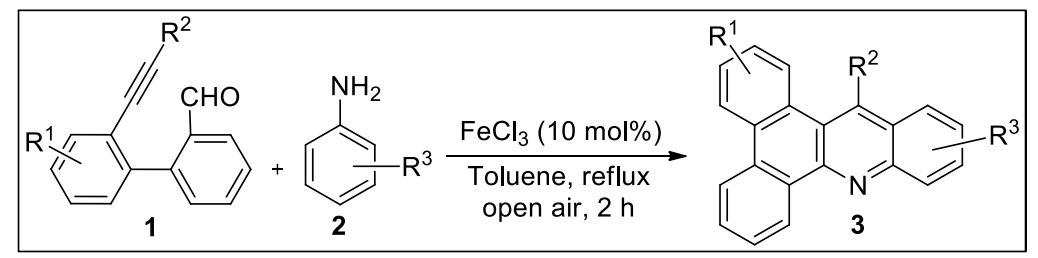

To an oven dried $25 \mathrm{~mL}$ round-bottom flask, 2'-Alkynylbiaryl-2-carbaldehyde $\mathbf{1}(0.3 \mathrm{mmol})$, aryl amine 2 (0.36 mmol), toluene $(2 \mathrm{~mL})$ and $\mathrm{FeCl}_{3}(0.03 \mathrm{mmol})$ were added. The mixture was stirred for 2 hours in open air at $100{ }^{\circ} \mathrm{C}$. After the completion of the reaction (monitored by TLC), the toluene was evaporated and the crude reaction mixture was purified by column chromatography on silica gel (100-200 mesh). A solution of ethyl acetate in petroleum ether was used to elute the desired product, dibenzo[ $[a, c]$ acridine derivative $\mathbf{3}$.

\section{Procedure for the 2 mmol-scale synthesis of 14-Phenyldibenzo[a,c]acridine (3aa)}

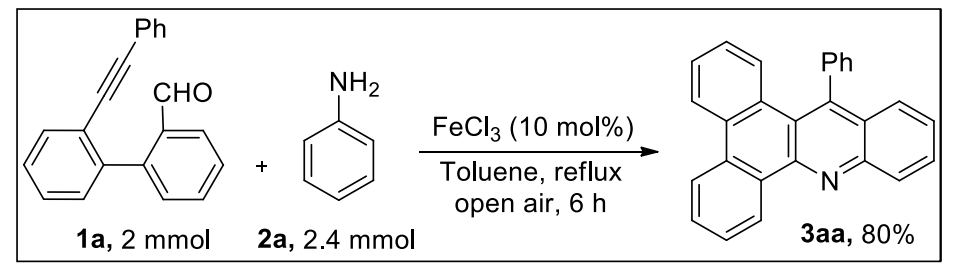

To an oven dried $50 \mathrm{~mL}$ round-bottom flask, 2'-(phenylethynyl)-[1,1'-biphenyl]-2-carbaldehyde (1a, $564 \mathrm{mg}, 2 \mathrm{mmol}$ ), aniline (2a, $223 \mathrm{mg}, 2.4 \mathrm{mmol})$, toluene $(12 \mathrm{~mL})$ and $\mathrm{FeCl}_{3}(32 \mathrm{mg}, 0.2 \mathrm{mmol})$ were added. The mixture was stirred for 6 hours in open air at $100^{\circ} \mathrm{C}$. After the completion of the reaction (monitored by TLC), the toluene was evaporated and the crude reaction mixture was purified by column chromatography on silica gel (100-200 mesh). A solution of $1 \%$ ethyl acetate in petroleum ether was used to elute the desired product 3aa $(568 \mathrm{mg}, 80 \%)$.

\section{Experimental procedure for the synthesis of 16-(p-Tolyl)tribenzo[a,c,h]acridine (5fa)}

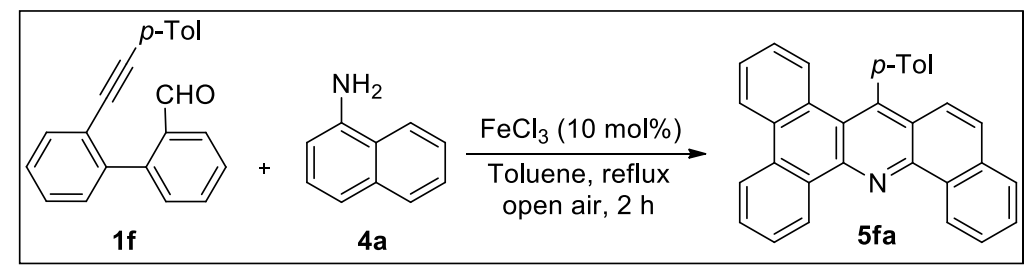


To an oven dried $25 \mathrm{~mL}$ round-bottom flask, 2'-Alkynylbiaryl-2-carbaldehyde $\mathbf{1 f}(0.3 \mathrm{mmol}), \alpha$-napthylamine $\mathbf{4 a}$ $(0.36 \mathrm{mmol})$, toluene $(2 \mathrm{~mL})$ and $\mathrm{FeCl}_{3}(0.03 \mathrm{mmol})$ were added. The mixture was stirred for 2 hours in open air at $100{ }^{\circ} \mathrm{C}$. After the completion of the reaction (monitored by TLC), the toluene was evaporated and the crude reaction mixture was purified by column chromatography on silica gel (100-200 mesh). A solution of $1 \%$ ethyl acetate in petroleum ether was used to elute the desired product 16-(p-Tolyl)tribenzo[a,c,h]acridine (5fa, $104 \mathrm{mg}, 83 \%)$. 
Absorption and Emission Spectra of the compounds
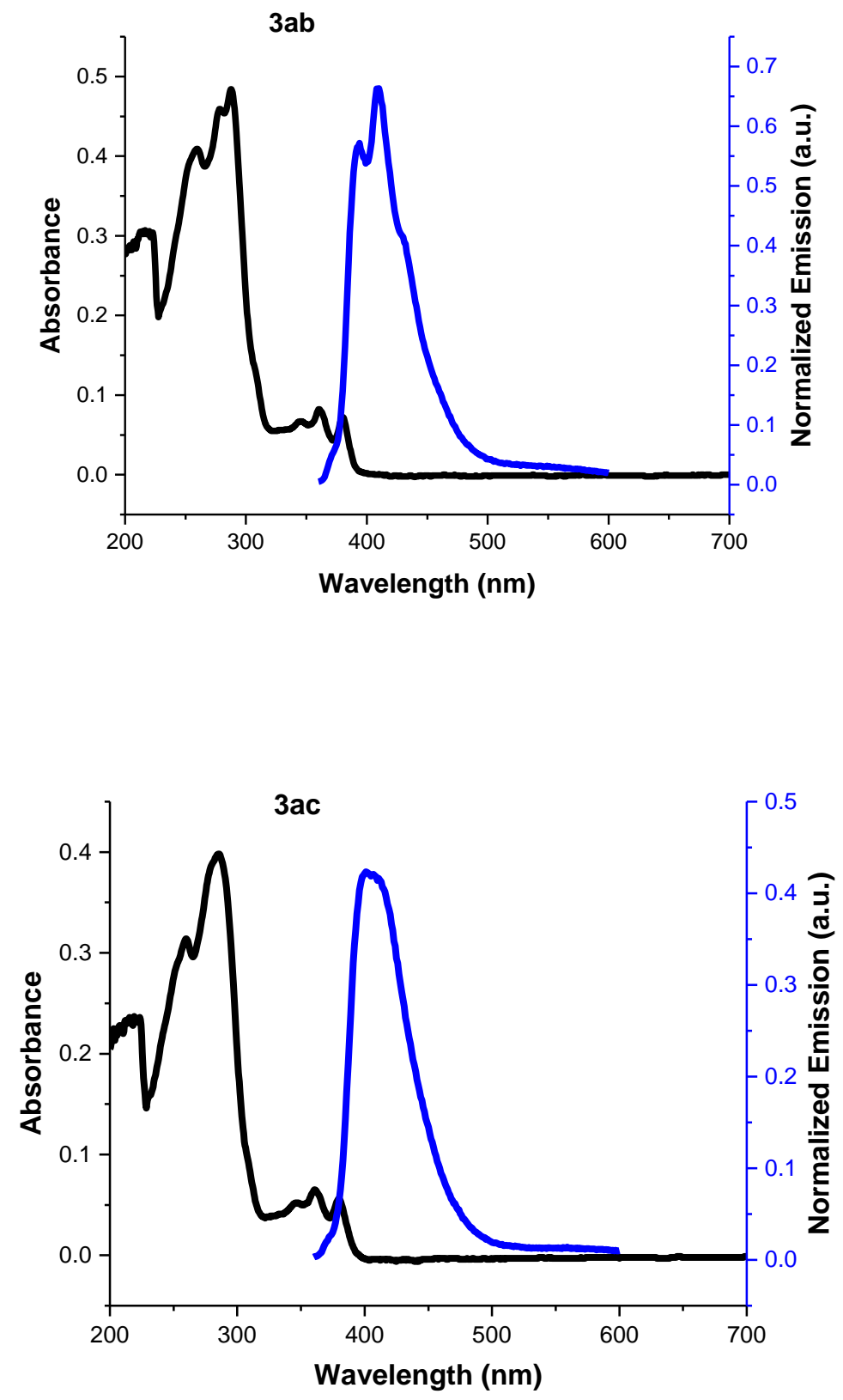

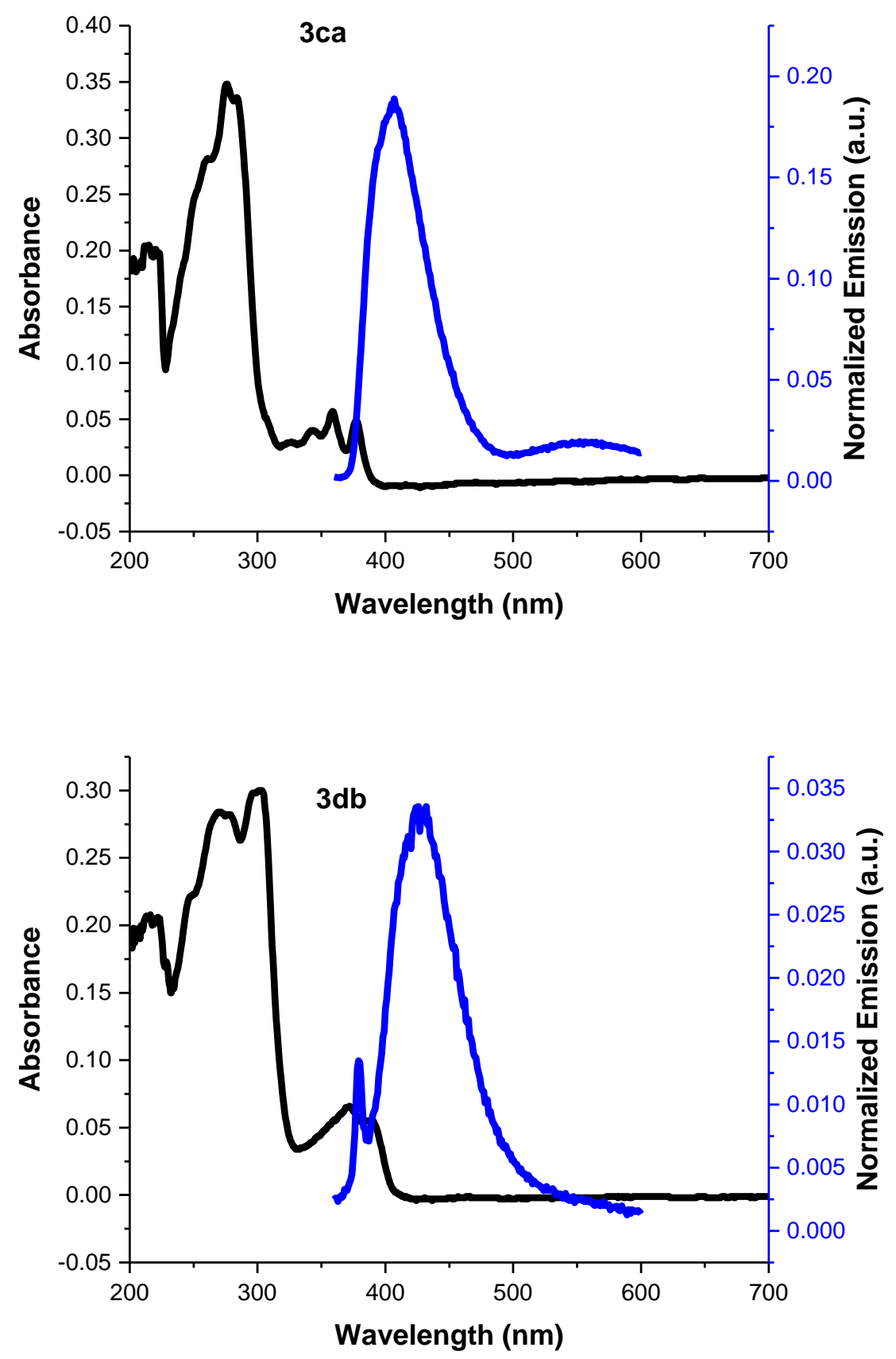

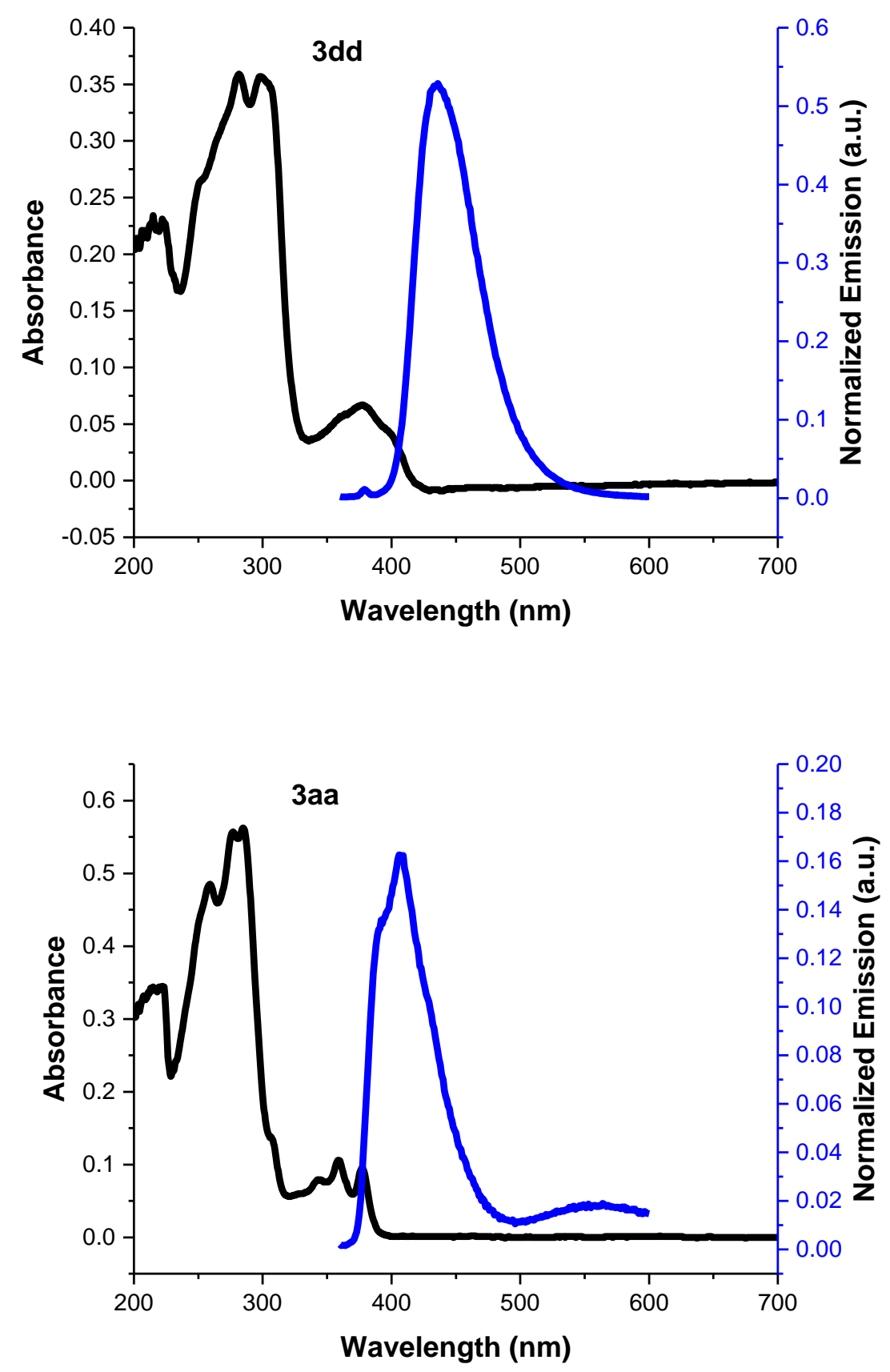

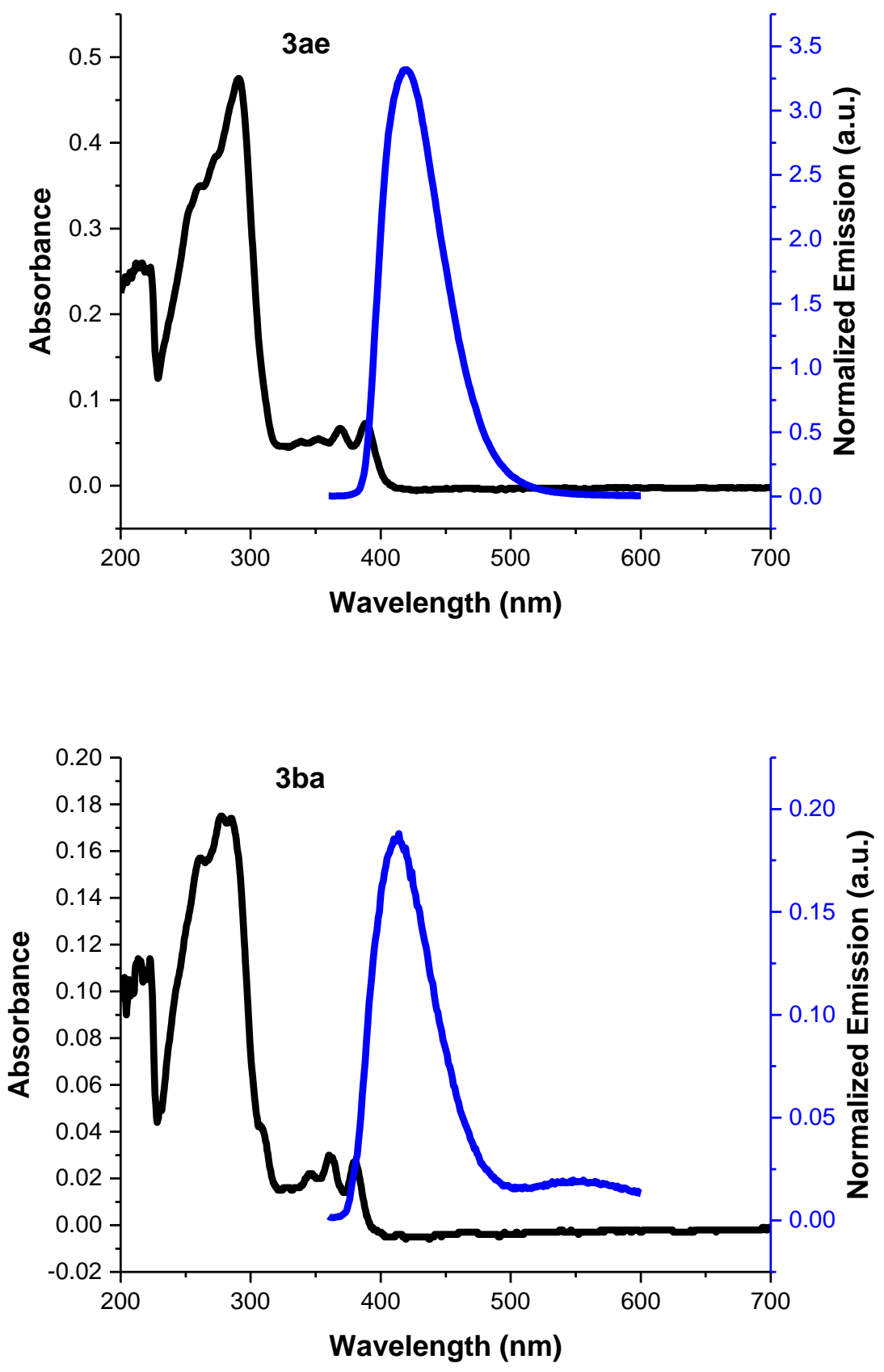

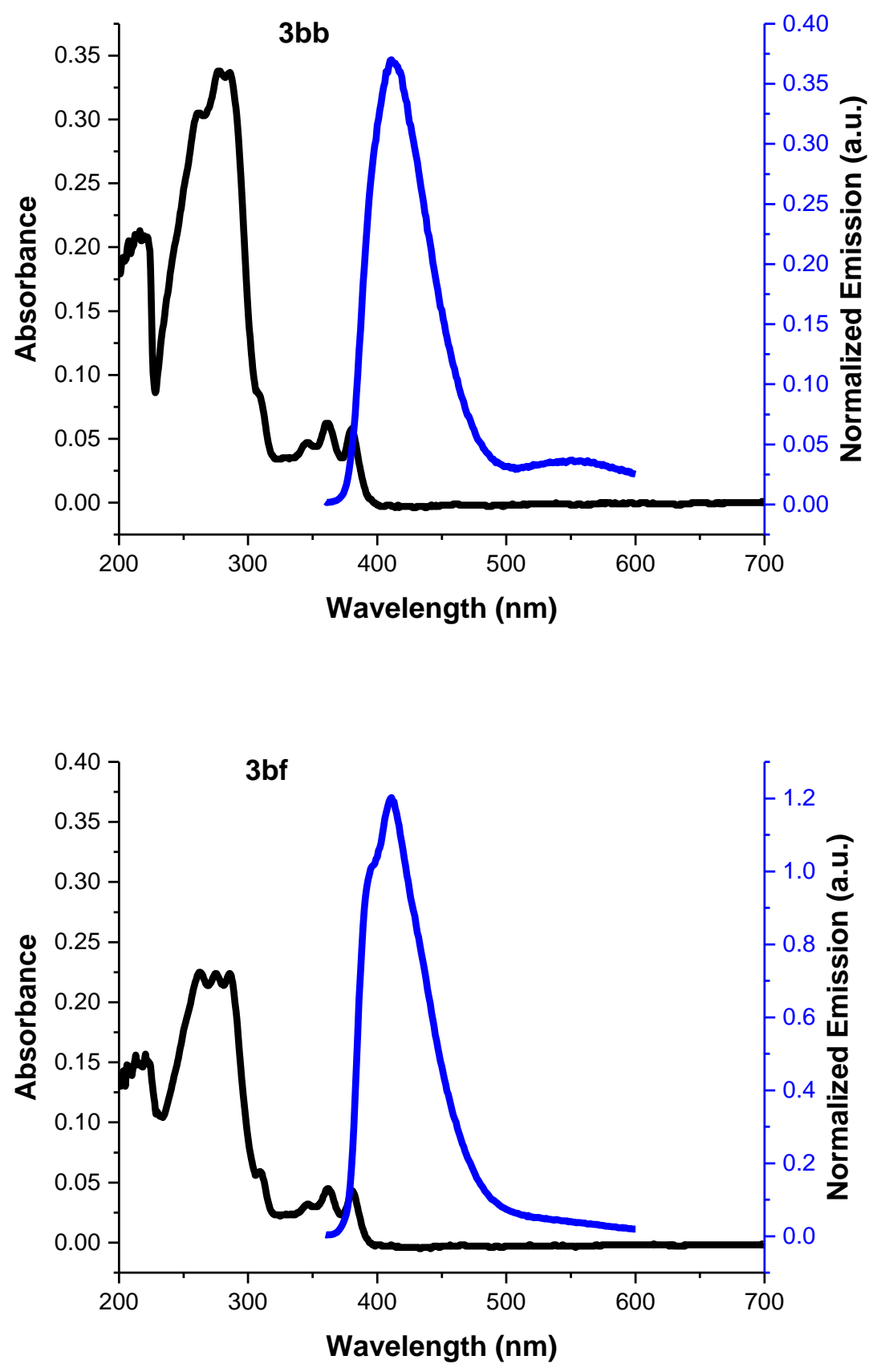

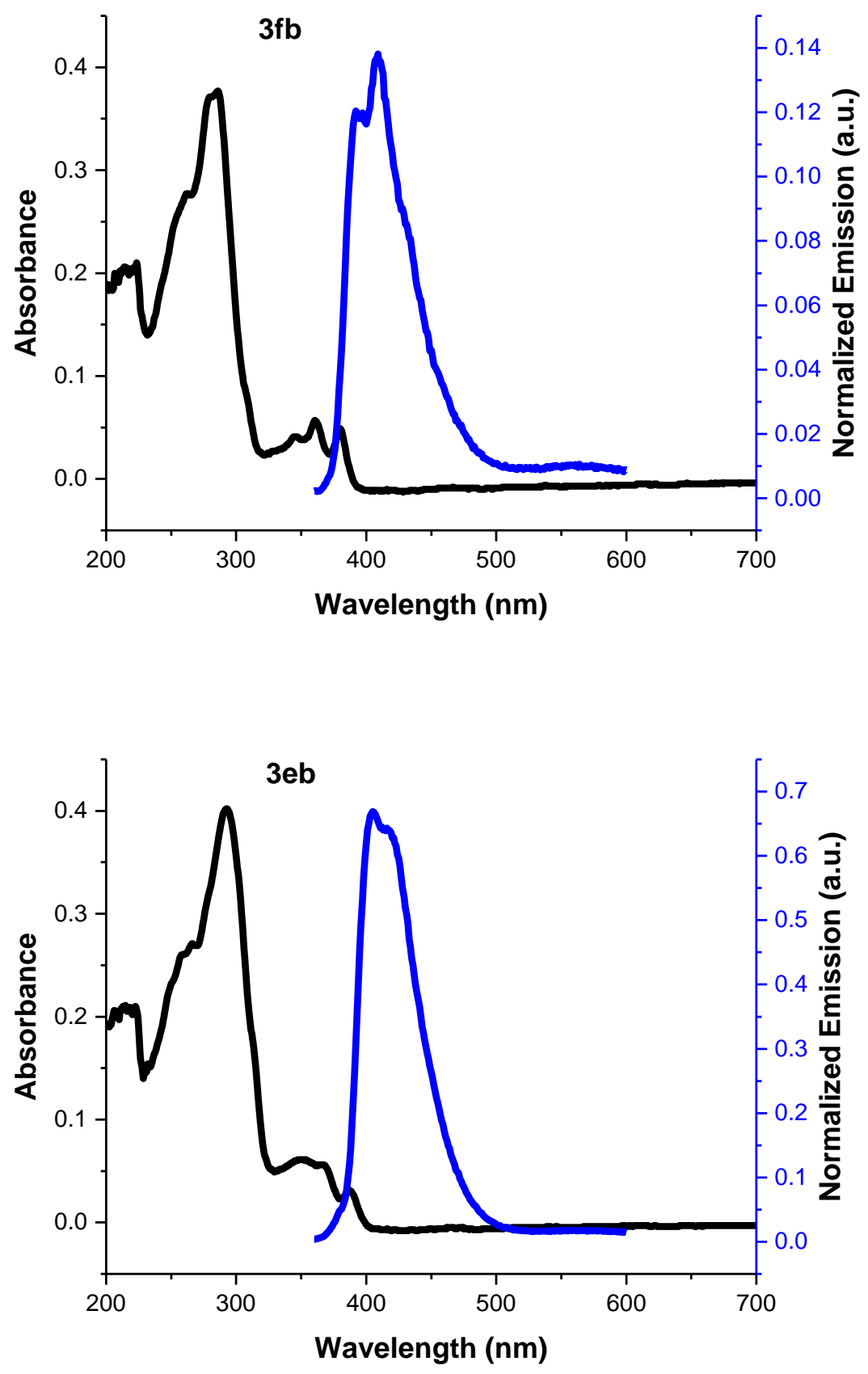


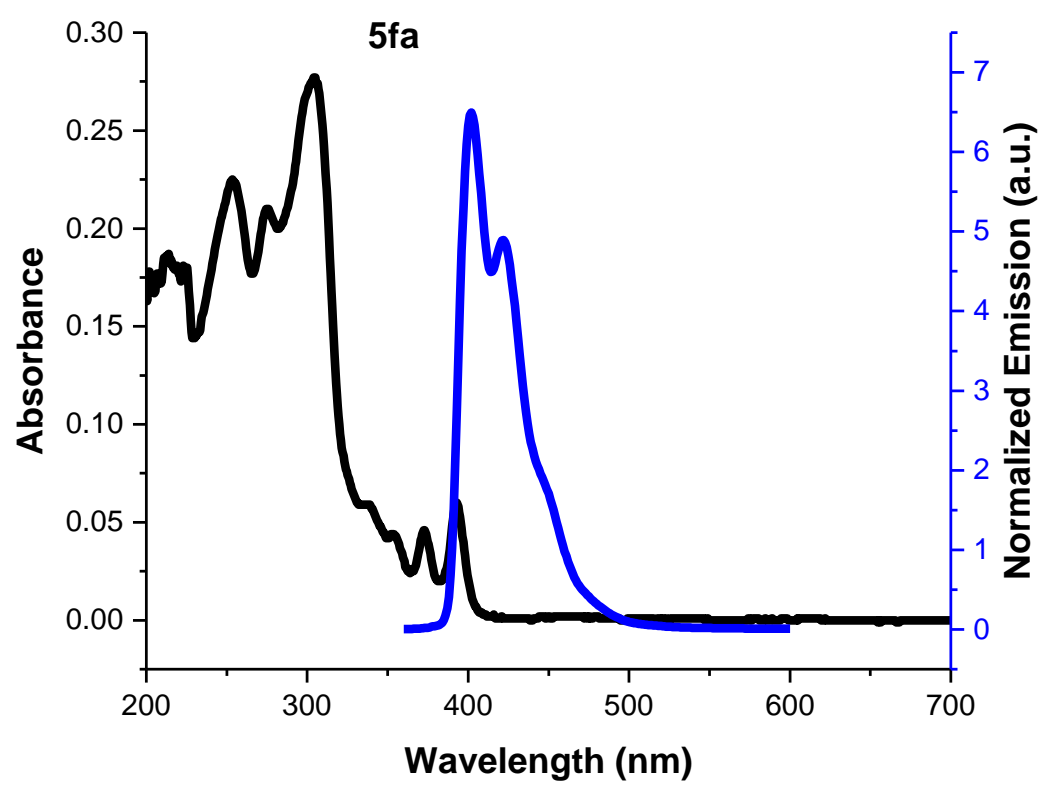


Figure S1. ORTEP diagram of the crystal structure of 3ad (ellipsoid contour at 50\% probability level)

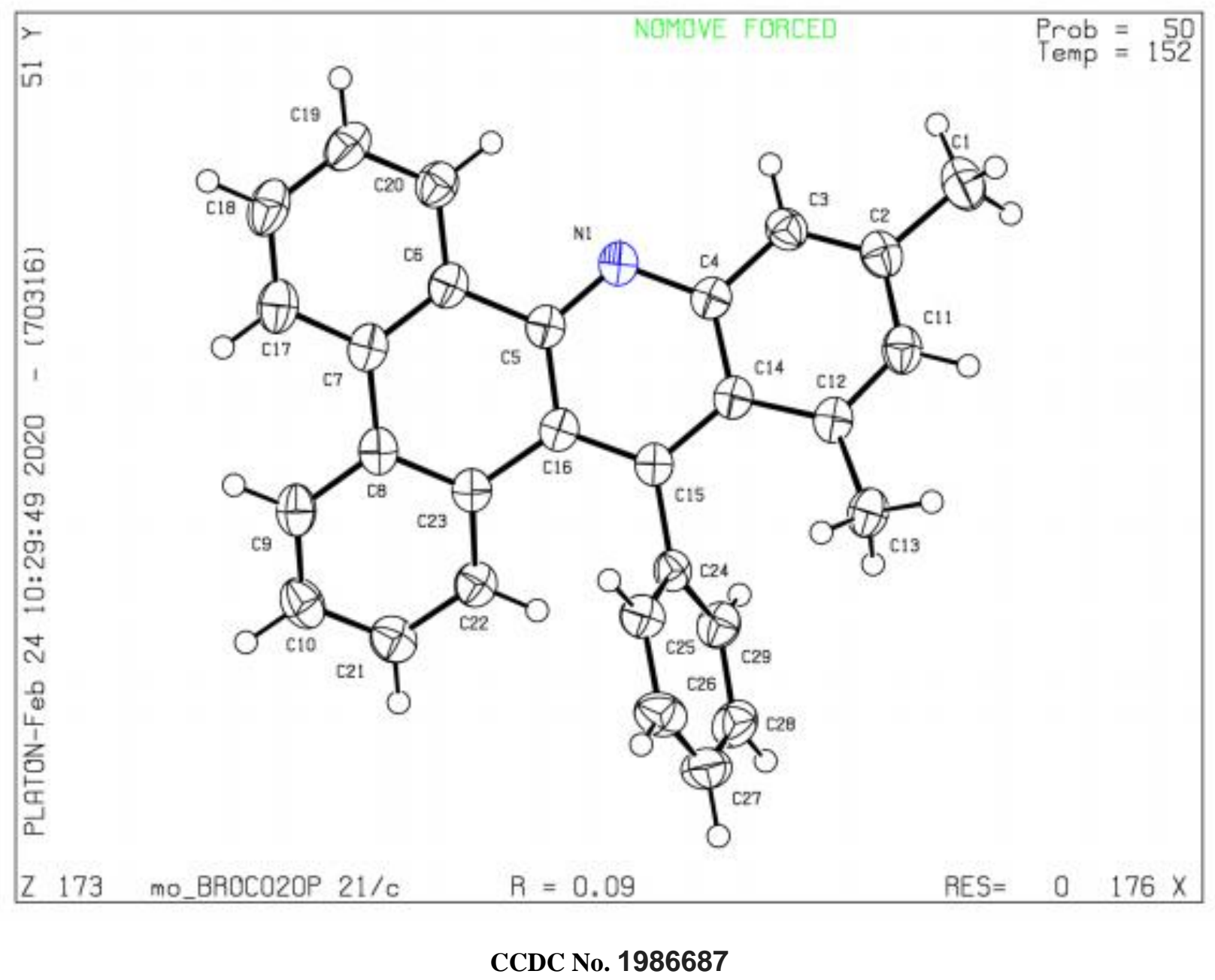




\section{Methods for the Sample Preparation and Crystal Measurements for the X-ray Crystallography for the Compound 3ad}

The single crystals of the compound 3ad were obtained by slow evaporation from a dilute solution of 3ad in ethyl acetate and petroleum ether at room temperature. Then, the single crystal was mounted on the tip of a thin glass fiber using ordinary glue. The crystal data of $\mathbf{3 a d}$ were collected then using a Bruker APEX II diffractometer having a sealed tube X-ray source with graphite monochromated Mo-K $\alpha$ radiation $(\lambda=0.71073 \AA)$. After collecting the data, the structure was solved by the program SHELXS 2017 using the Patterson method, followed by successive Fourier and difference Fourier synthesis. The structure was refined with SHELXL-2017 using full matrix least-squares method. Refinement was performed on F2 anisotropically for all non-hydrogen atoms. All hydrogen atoms were fixed geometrically by HFIX command and placed in ideal positions. The crystallographic data and the structure refinement parameters are given in Table S1.

Table S1. Table for crystallographic data and structural refinement parameters for 3ad

\begin{tabular}{|c|c|c|}
\hline Identification code & \multicolumn{2}{|c|}{ mo_BROC020919_0m } \\
\hline Empirical formula & \multicolumn{2}{|l|}{$\mathrm{C} 29 \mathrm{H} 21 \mathrm{~N}$} \\
\hline Formula weight & \multicolumn{2}{|l|}{383.47} \\
\hline Temperature & \multicolumn{2}{|l|}{$152(2) \mathrm{K}$} \\
\hline Wavelength & \multicolumn{2}{|l|}{$0.71073 \AA$} \\
\hline Crystal system & \multicolumn{2}{|l|}{ monoclinic } \\
\hline Space group & \multicolumn{2}{|l|}{$\mathrm{P} 21 / \mathrm{c}$} \\
\hline \multirow{3}{*}{ Unit cell dimensions } & $\mathrm{a}=9.4336(13) \AA$ & $\alpha=90^{\circ}$ \\
\hline & $\mathrm{b}=19.646(3) \AA$ & $\beta=106.121(5)^{\circ}$ \\
\hline & $\mathrm{c}=10.9945(14) \AA$ & $\gamma=90^{\circ}$ \\
\hline Cell volume & \multicolumn{2}{|l|}{$1957.5(5) \AA^{3}$} \\
\hline $\bar{Z}$ & \multicolumn{2}{|l|}{4} \\
\hline Density & \multicolumn{2}{|l|}{$1.301 \mathrm{mg} / \mathrm{m}^{3}$} \\
\hline Absorption coefficient & \multicolumn{2}{|l|}{$0.075 \mathrm{~mm}^{-1}$} \\
\hline $\mathrm{F}(000)$ & \multicolumn{2}{|l|}{808} \\
\hline Crystal size & \multicolumn{2}{|l|}{$0.3 \times 0.2 \times 0.1 \mathrm{~mm}^{3}$} \\
\hline Theta range for data collection & \multicolumn{2}{|l|}{$2.189^{\circ}$ to $25.749^{\circ}$} \\
\hline Index ranges & \multicolumn{2}{|c|}{$-11<=\mathrm{h}<=11,-23<=\mathrm{k}<=23,-11<=1<=13$} \\
\hline Reflections number & \multicolumn{2}{|l|}{19427} \\
\hline Unique reflections & \multicolumn{2}{|l|}{3712} \\
\hline Reflections $I>2 \sigma(\mathrm{I})$ & \multicolumn{2}{|l|}{2380} \\
\hline$R_{\text {int }}$ & \multicolumn{2}{|l|}{0.1679} \\
\hline Goodness-of-fit $\left(F^{2}\right)$ & \multicolumn{2}{|l|}{1.065} \\
\hline Largest diff. peak/hole / e $\AA^{-3}$ & \multicolumn{2}{|l|}{$0.380,-0.435$} \\
\hline
\end{tabular}




\section{${ }^{1} \mathrm{H}$ NMR and ${ }^{13} \mathrm{C}$ NMR spectra}

${ }^{1} \mathrm{H}$ NMR (400 MHz, CDCl 3$)$ of the compound 3aa

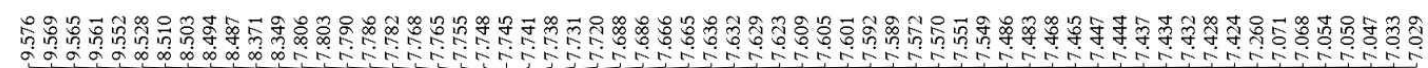
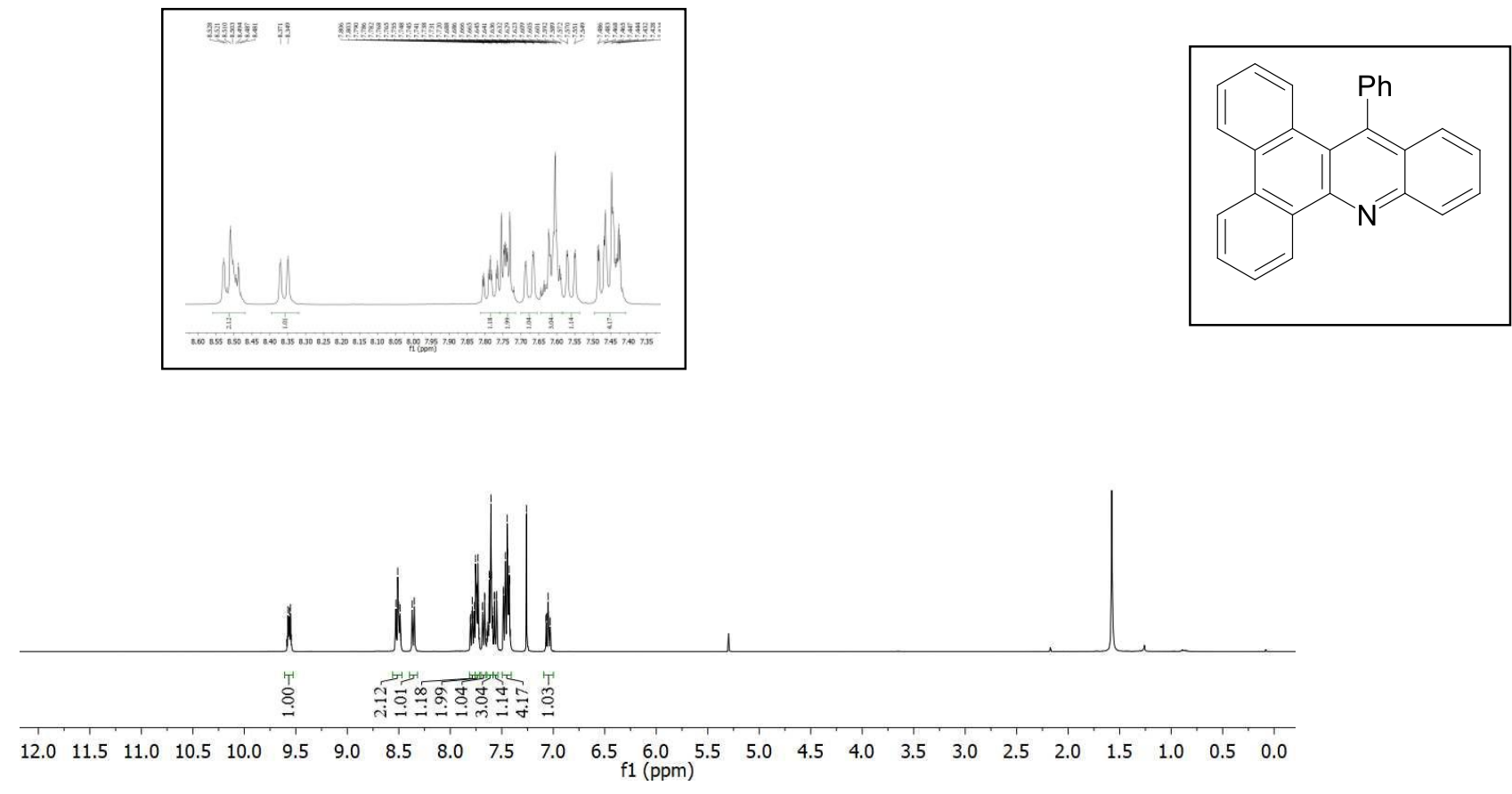

${ }^{13} \mathrm{C}$ NMR (100 $\left.\mathrm{MHz}, \mathrm{CDCl}_{3}\right)$ of the compound 3aa

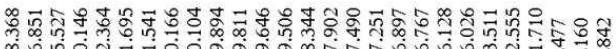

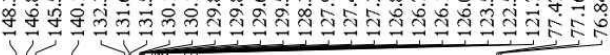
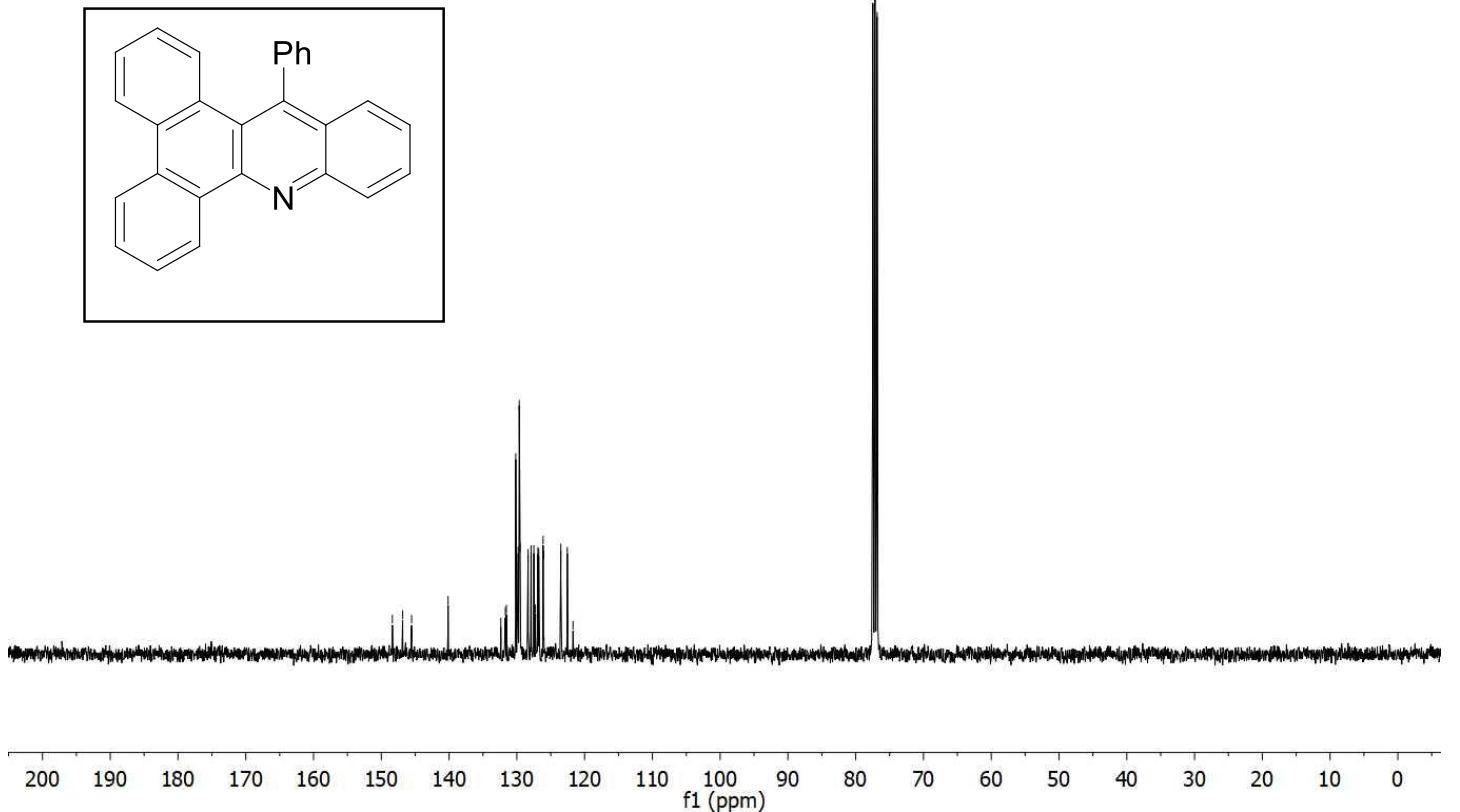
${ }^{1} \mathrm{H}$ NMR (400 $\mathrm{MHz}, \mathrm{CDCl}_{3}$ ) of the compound 3ba

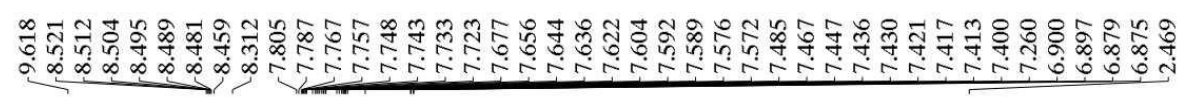
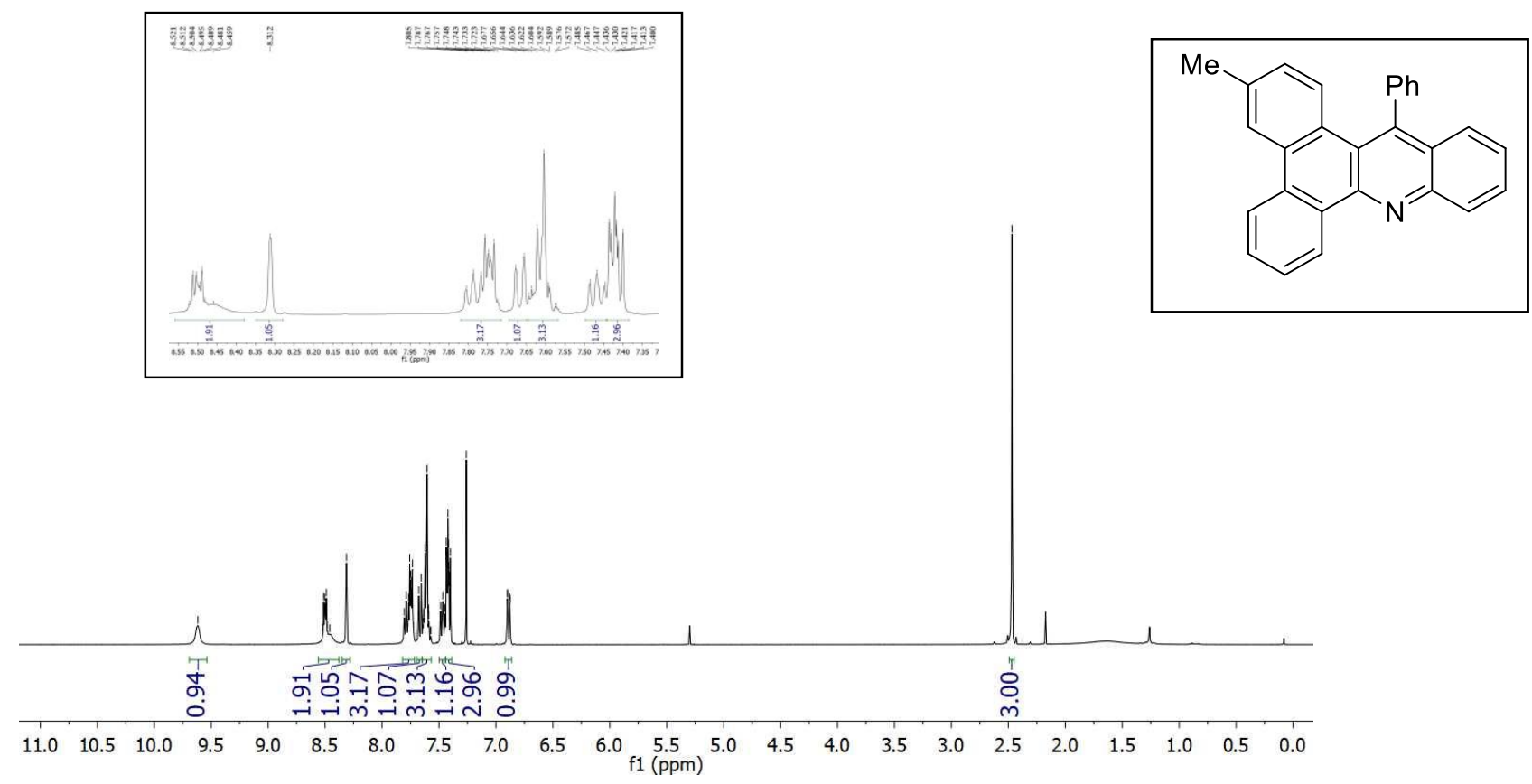

${ }^{13} \mathrm{C}$ NMR (100 MHz, $\left.\mathrm{CDCl}_{3}\right)$ of the compound 3ba

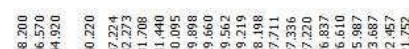

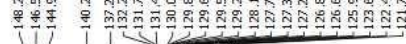
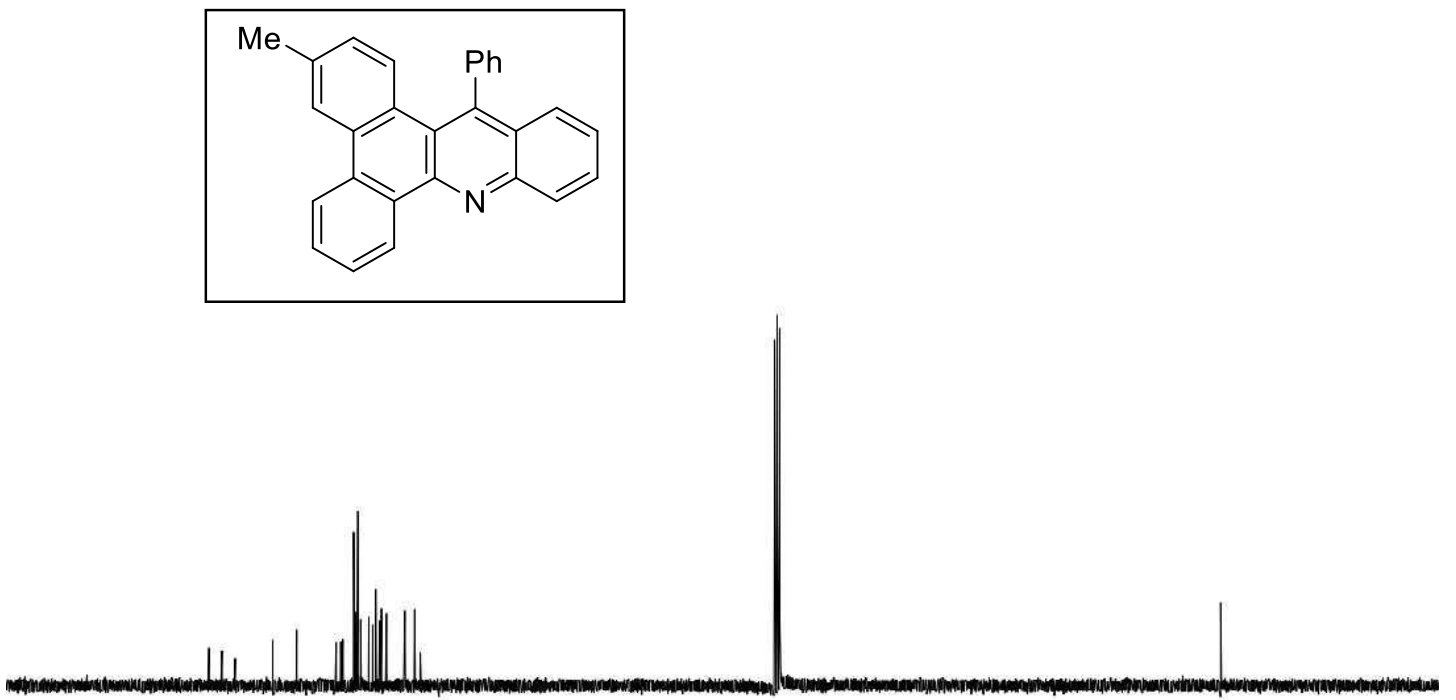

$\begin{array}{lllllllll}170 & 160 & 150 & 140 & 130 & 120 & 110 & 100 & 90 \\ & & & & & 80\end{array}$ 
${ }^{1} \mathrm{H}$ NMR (400 MHz, $\mathrm{CDCl}_{3}$ ) of the compound 3ca

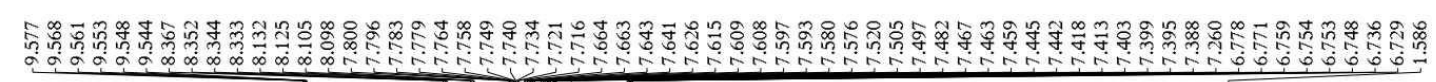
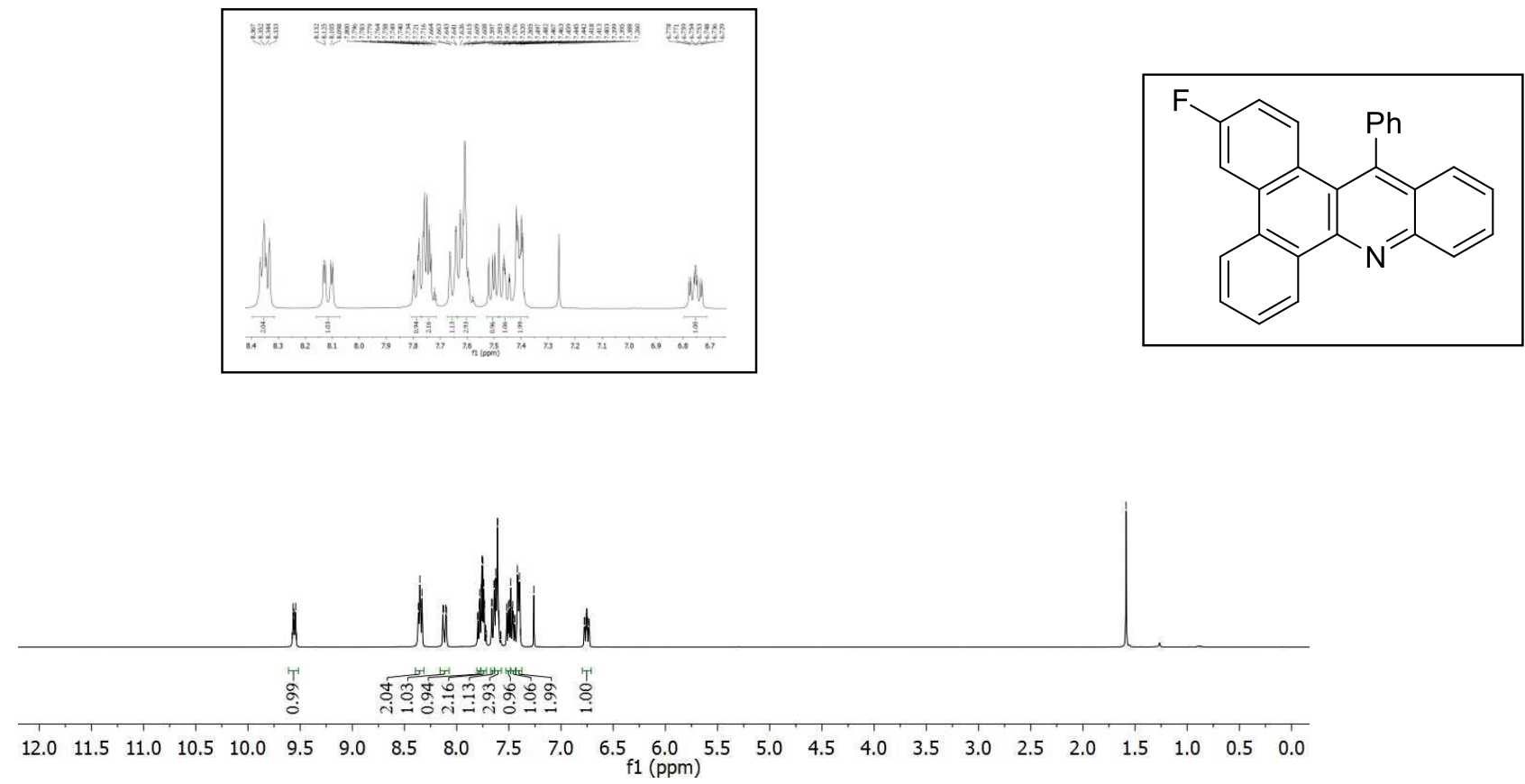

${ }^{13} \mathrm{C}$ NMR (100 MHz, $\left.\mathrm{CDCl}_{3}\right)$ of the compound 3ca
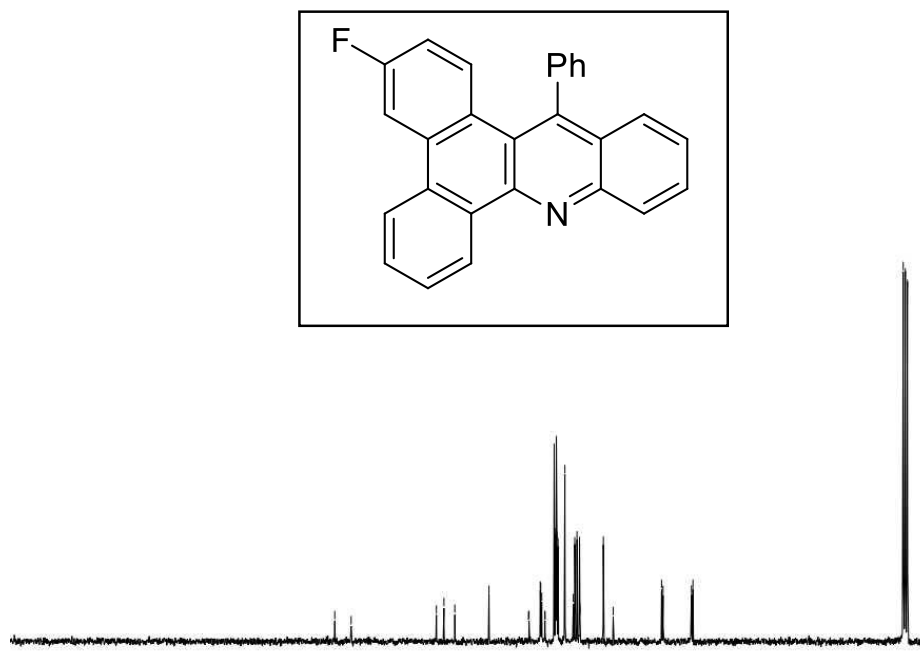

$\begin{array}{lllllllllll}210 & 200 & 190 & 180 & 170 & 160 & 150 & 140 & 130 & 120 & \begin{array}{c}110 \\ \mathrm{f} 1(\mathrm{ppm})\end{array}\end{array}$

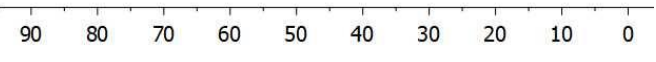


${ }^{1} \mathrm{H}$ NMR (400 $\left.\mathrm{MHz}, \mathrm{CDCl}_{3}\right)$ of the compound 3ab

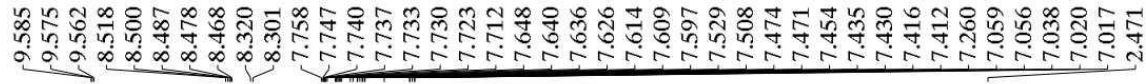
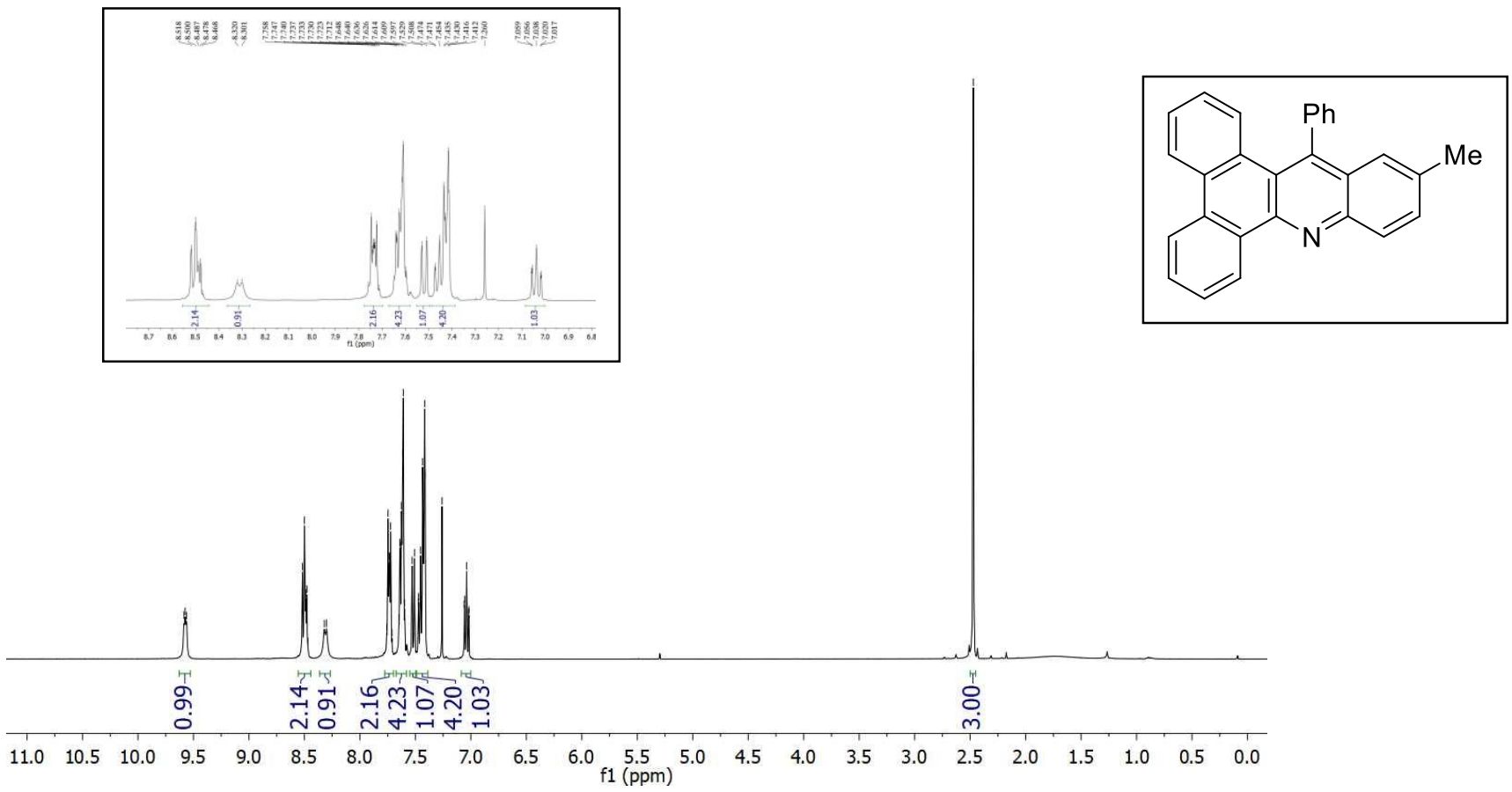

${ }^{13} \mathrm{C}$ NMR (100 MHz, $\left.\mathrm{CDCl}_{3}\right)$ of the compound 3ab

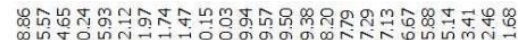

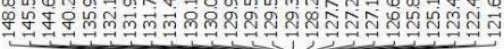
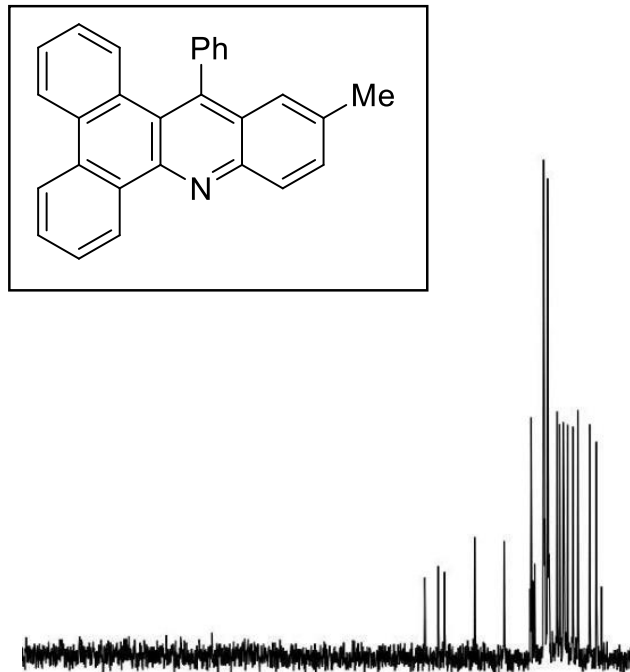
${ }^{1} \mathrm{H}$ NMR (400 MHz, $\left.\mathrm{CDCl}_{3}\right)$ of the compound 3ac

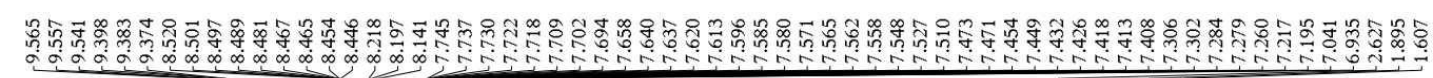
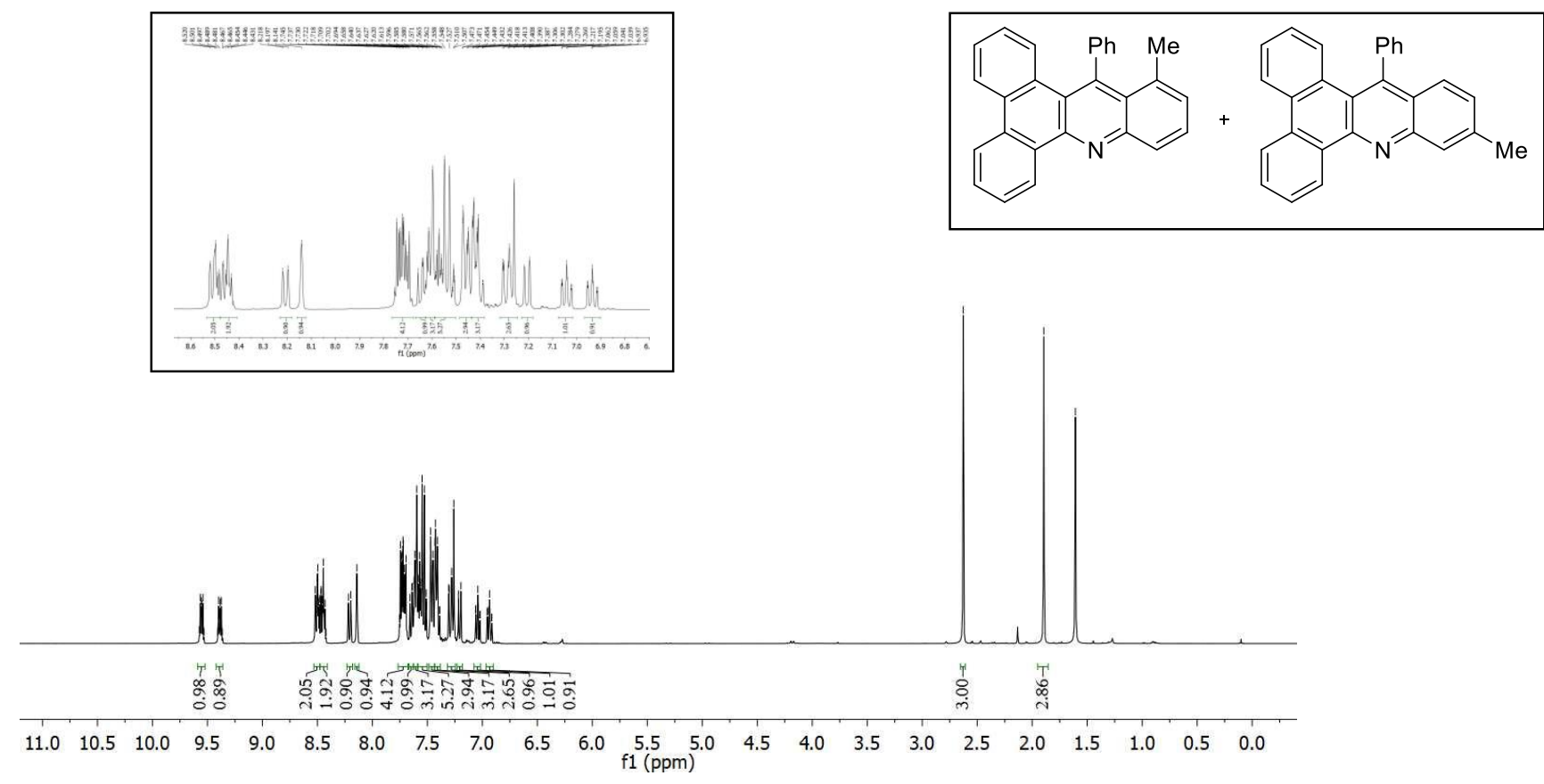

${ }^{13} \mathrm{C}$ NMR (100 MHz, $\left.\mathrm{CDCl}_{3}\right)$ of the compound 3ac

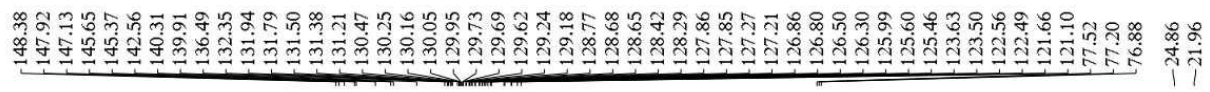
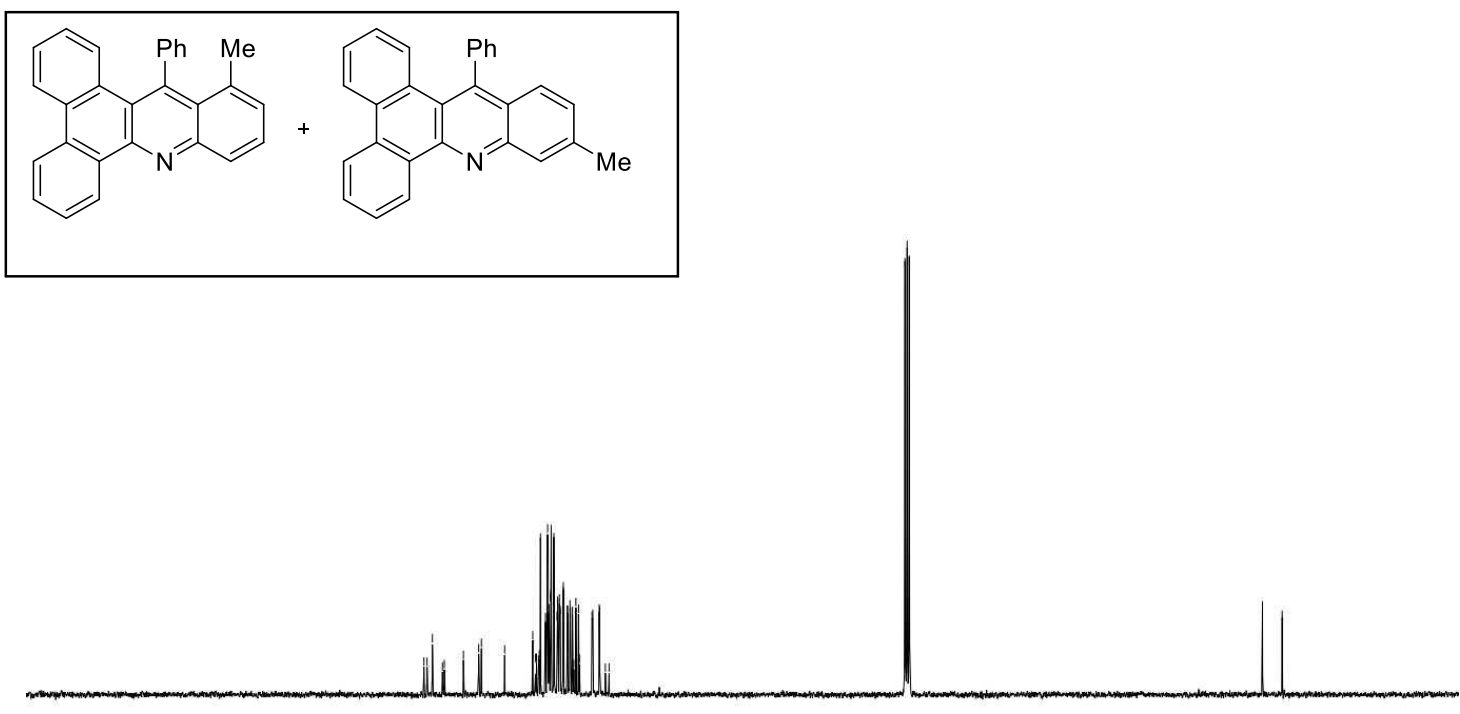

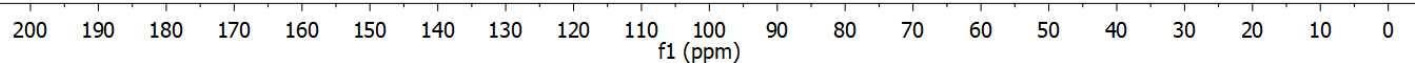


${ }^{1} \mathrm{H}$ NMR (400 MHz, $\mathrm{CDCl}_{3}$ ) of the compound 3ad

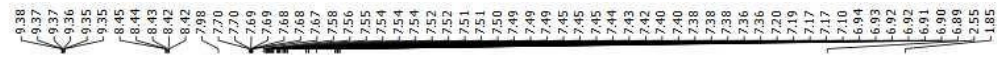
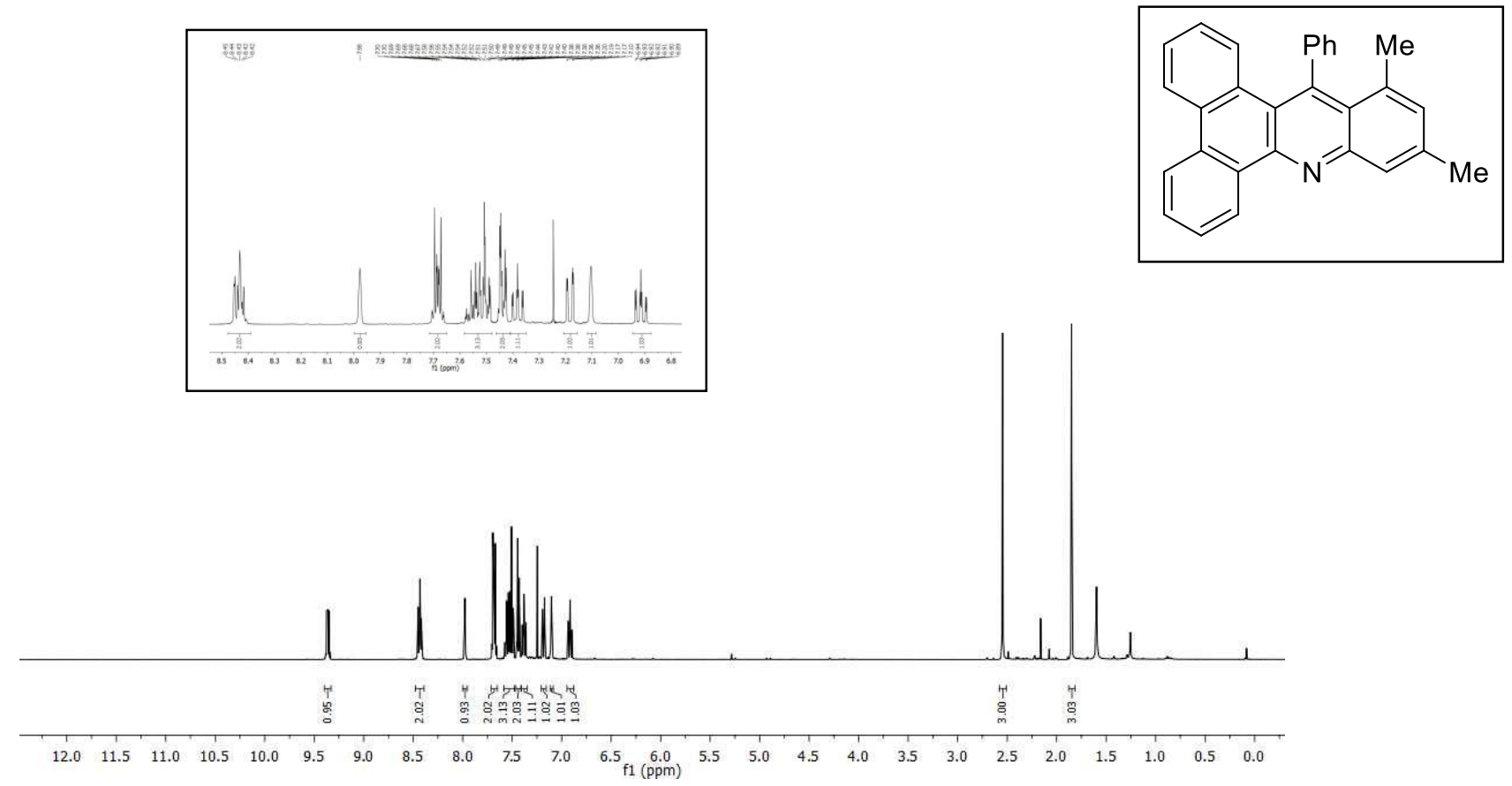

${ }^{13} \mathrm{C}$ NMR (100 MHz, $\mathrm{CDCl}_{3}$ ) of the compound 3ad

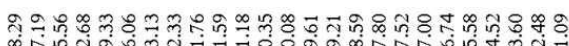

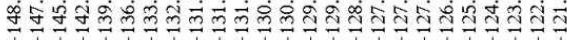

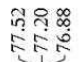

范鱼<smiles>Cc1cc(C)c2c(-c3ccccc3)c3c4ccccc4c4ccccc4c3nc2c1</smiles>

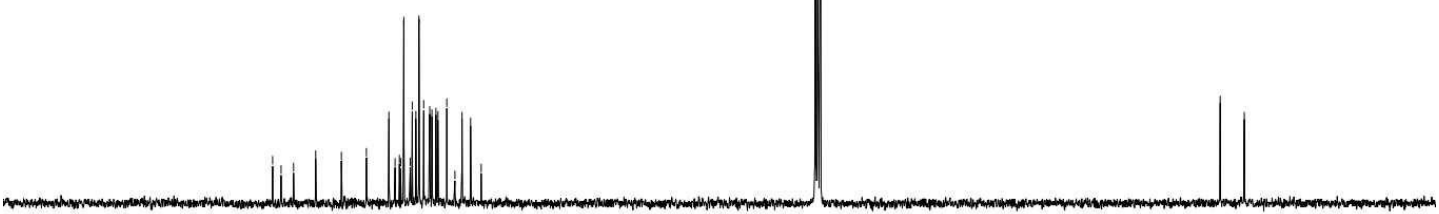


${ }^{1} \mathrm{H}$ NMR (400 MHz, $\left.\mathrm{CDCl}_{3}\right)$ of the compound 3ae

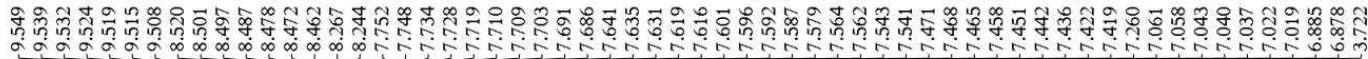
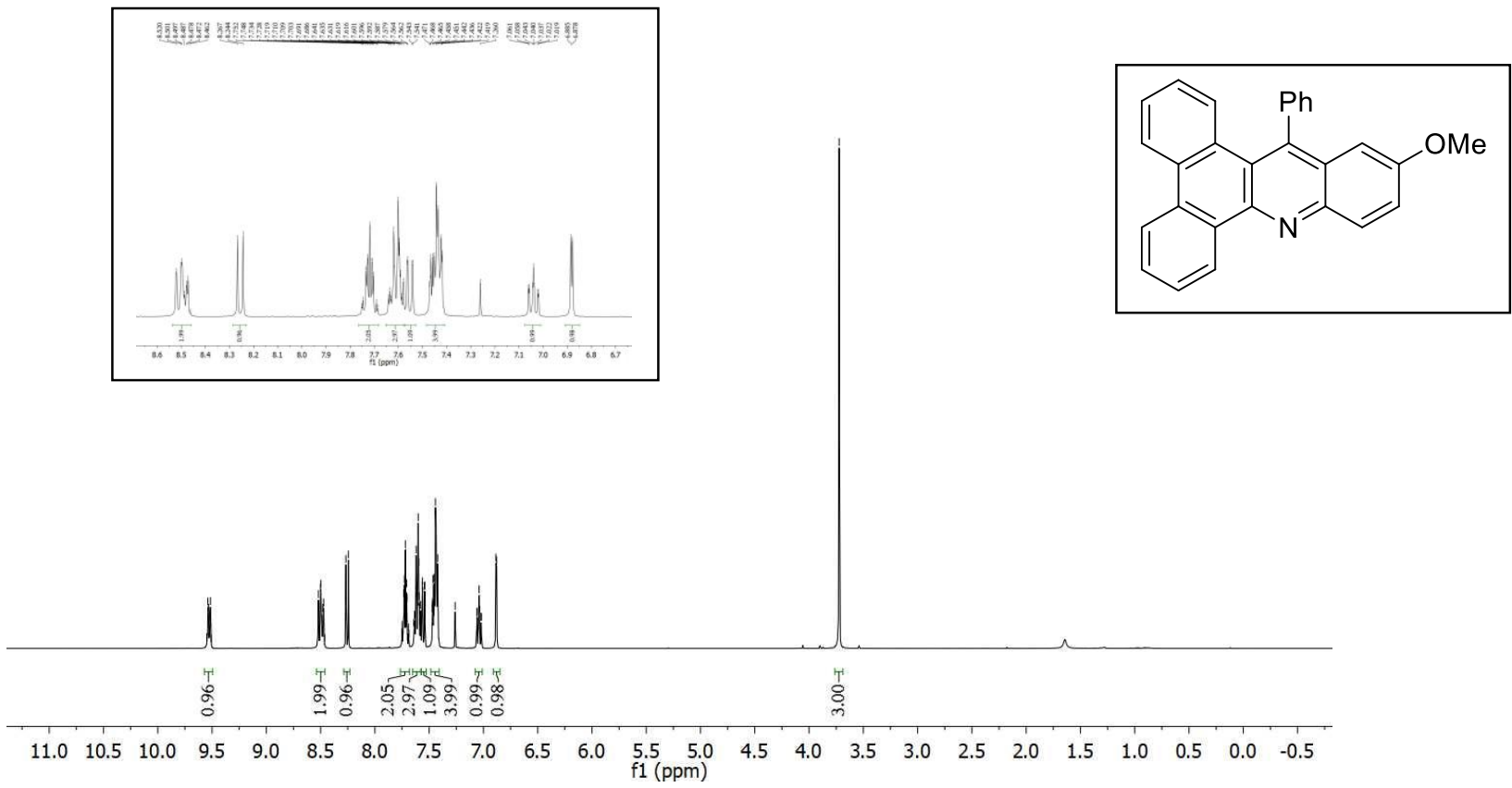

${ }^{13} \mathrm{C}$ NMR (100 MHz, $\left.\mathrm{CDCl}_{3}\right)$ of the compound 3ae
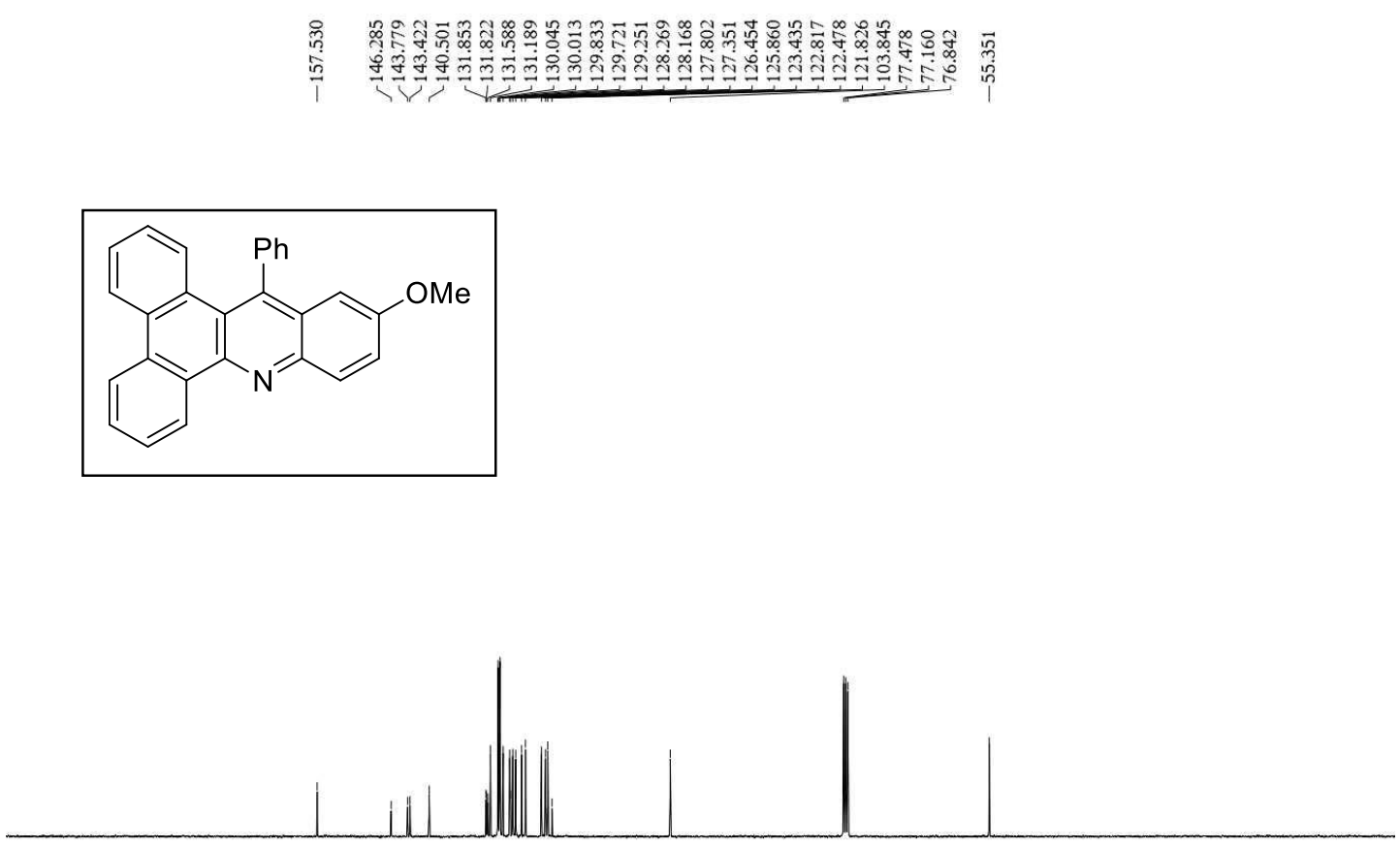

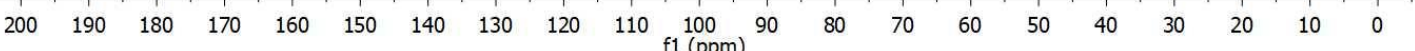


${ }^{1} \mathrm{H}$ NMR (400 MHz, $\left.\mathrm{CDCl}_{3}\right)$ of the compound 3af

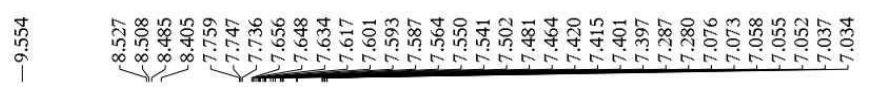
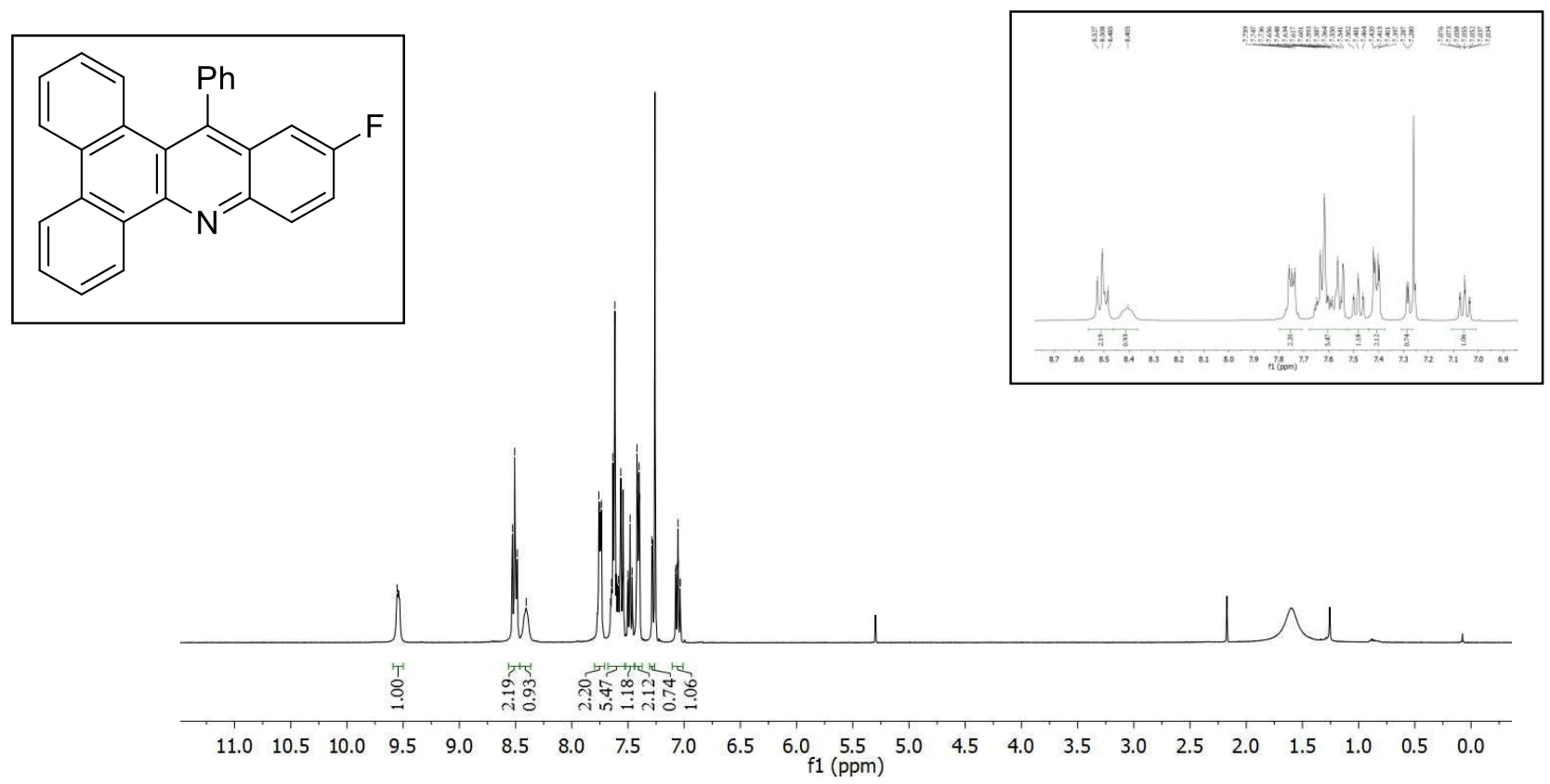

${ }^{13} \mathrm{C}$ NMR (100 $\left.\mathrm{MHz}, \mathrm{CDCl}_{3}\right)$ of the compound 3af

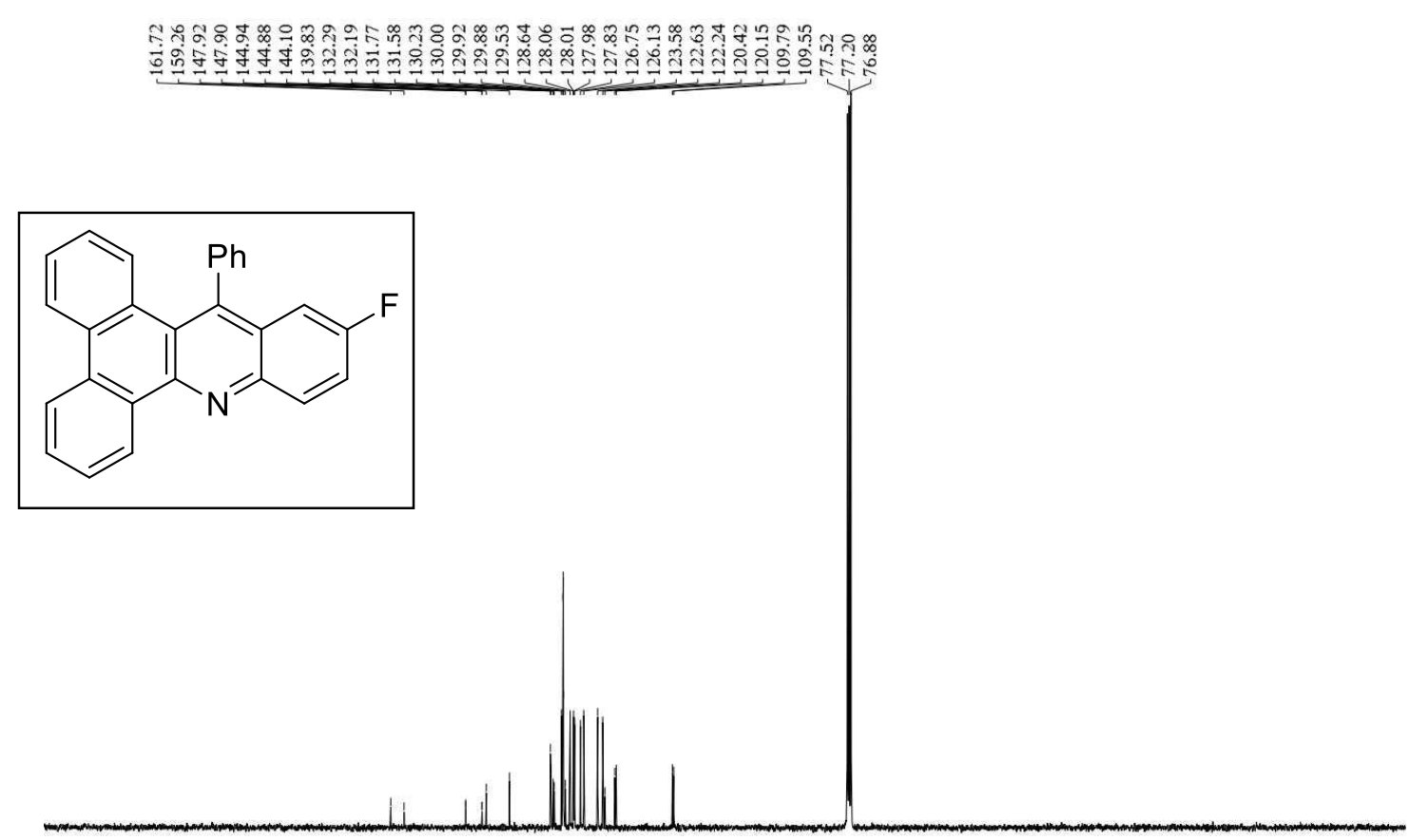

$\begin{array}{llllllllllllllllllllllllllll}220 & 210 & 200 & 190 & 180 & 170 & 160 & 150 & 140 & 130 & 120 & 110 & 100 & 90 & 80 & 70 & 60 & 50 & 40 & 30 & 20 & 10 & 0 & -10 & -20\end{array}$ 
${ }^{1} \mathrm{H}$ NMR (400 $\left.\mathrm{MHz}, \mathrm{CDCl}_{3}\right)$ of the compound $3 \mathrm{bb}$
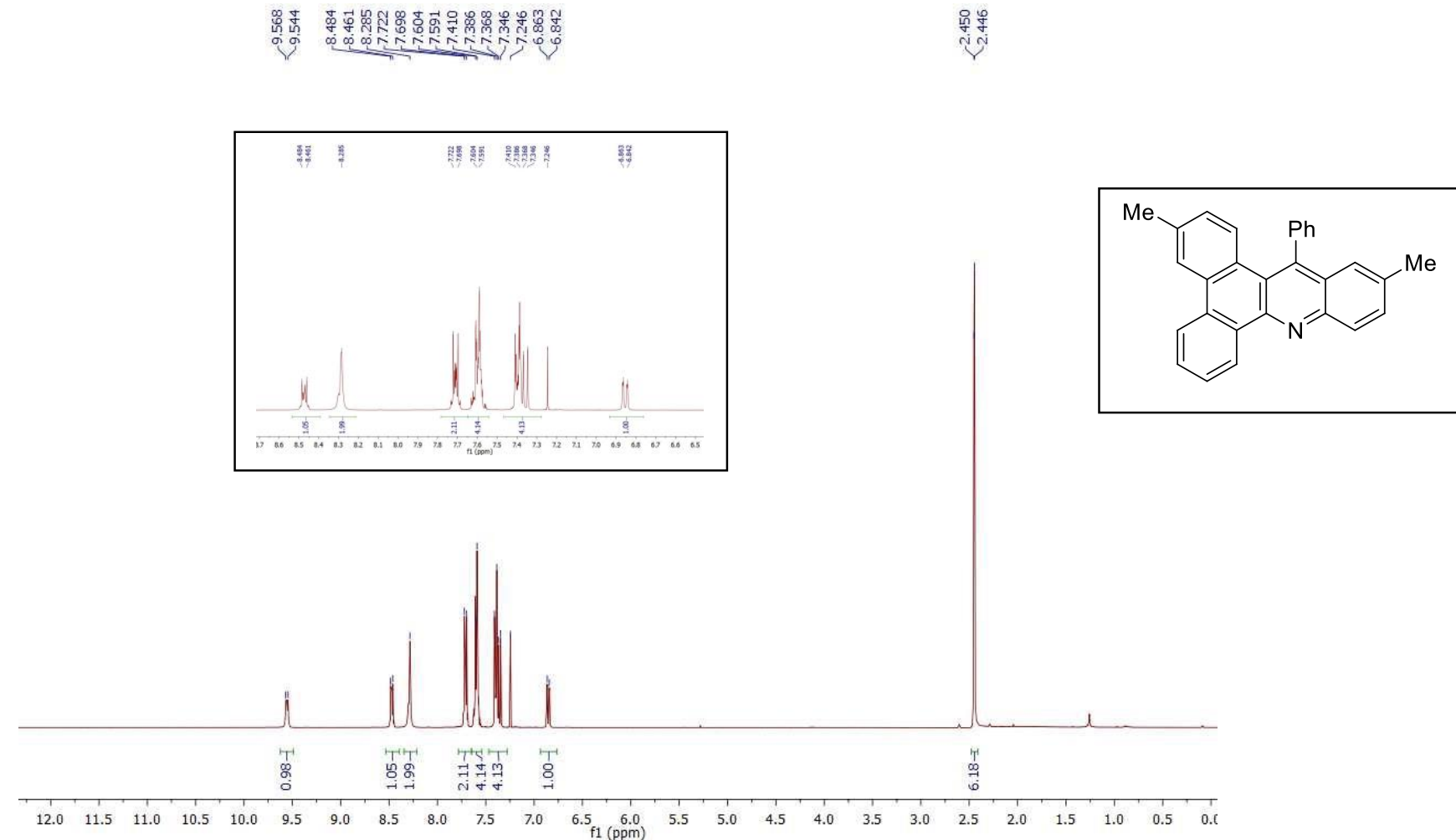

${ }^{13} \mathrm{C}$ NMR (100 $\left.\mathrm{MHz}, \mathrm{CDCl}_{3}\right)$ of the compound $3 \mathrm{bb}$

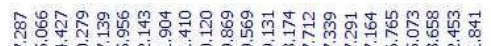

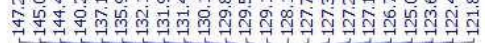

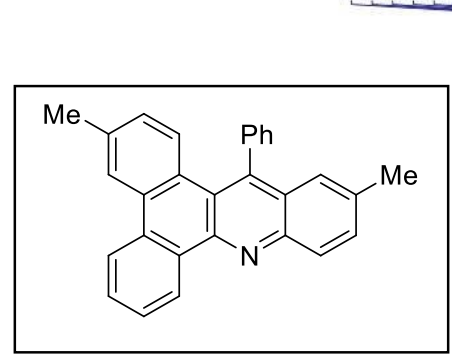

$\begin{array}{lllllllllll}10 & 200 & 190 & 180 & 170 & 160 & 150 & 140 & 130 & 120 & 110 \underset{\mathrm{f} 1(\mathrm{ppm})}{100}\end{array}$ 
${ }^{1} \mathrm{H}$ NMR (400 MHz, $\mathrm{CDCl}_{3}$ ) of the compound $3 \mathrm{db}$

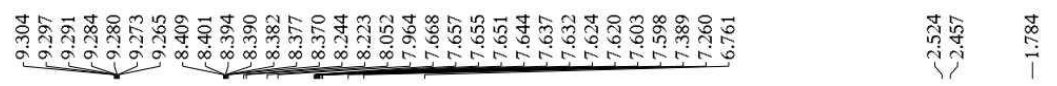

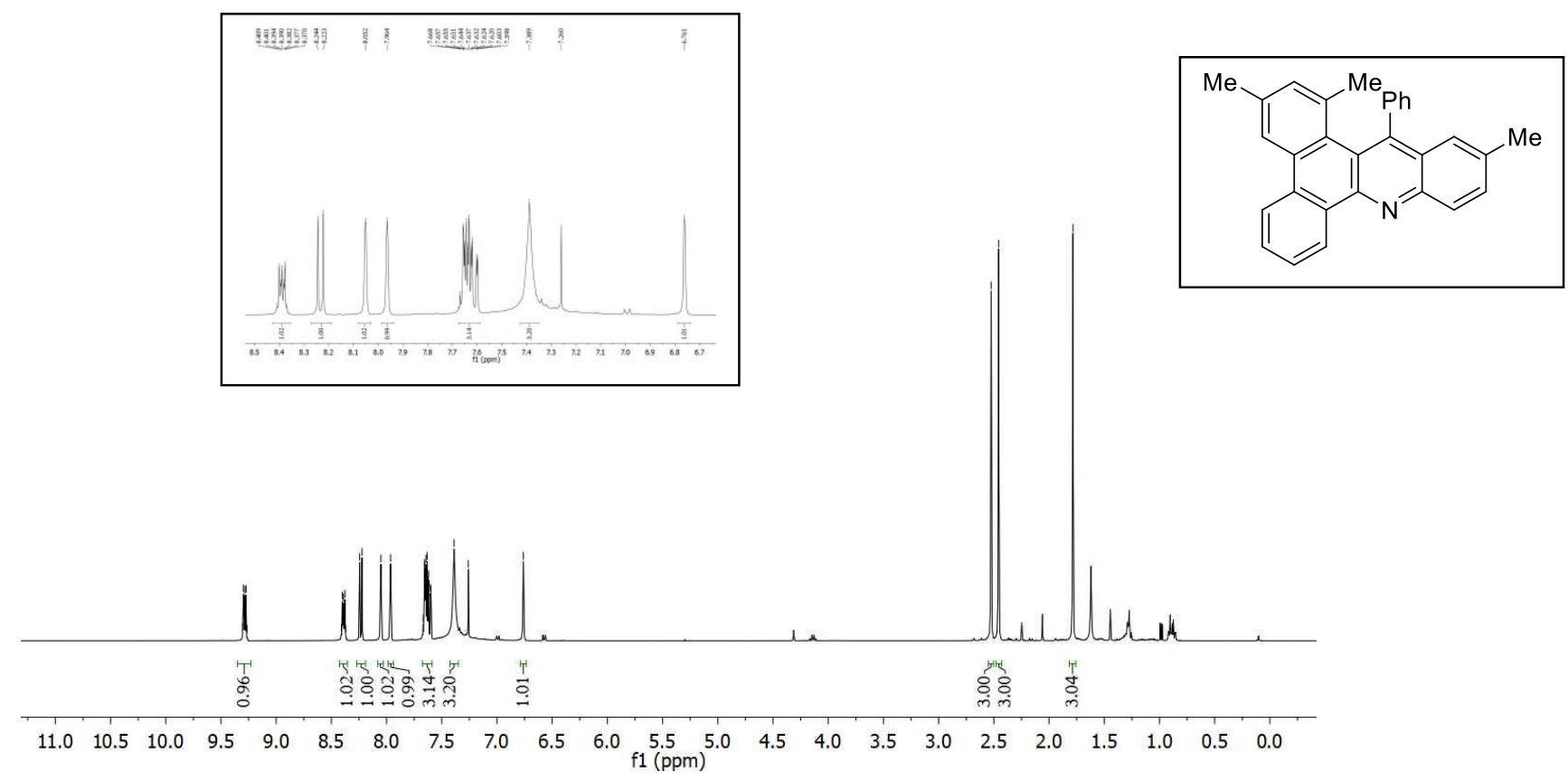

${ }^{13} \mathrm{C}$ NMR (100 $\left.\mathrm{MHz}, \mathrm{CDCl}_{3}\right)$ of the compound $3 \mathrm{db}$

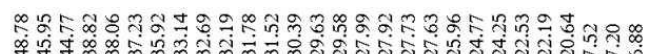

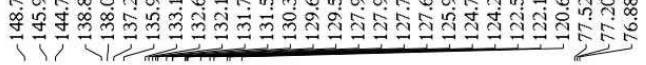
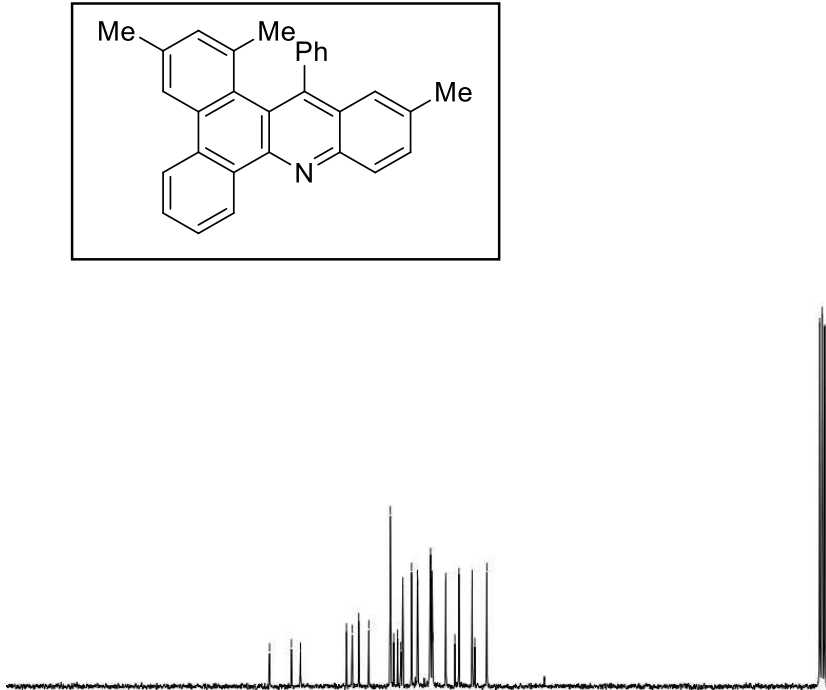

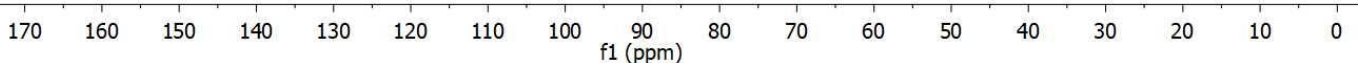


${ }^{1} \mathrm{H}$ NMR (400 $\left.\mathrm{MHz}, \mathrm{CDCl}_{3}\right)$ of the compound 3dd
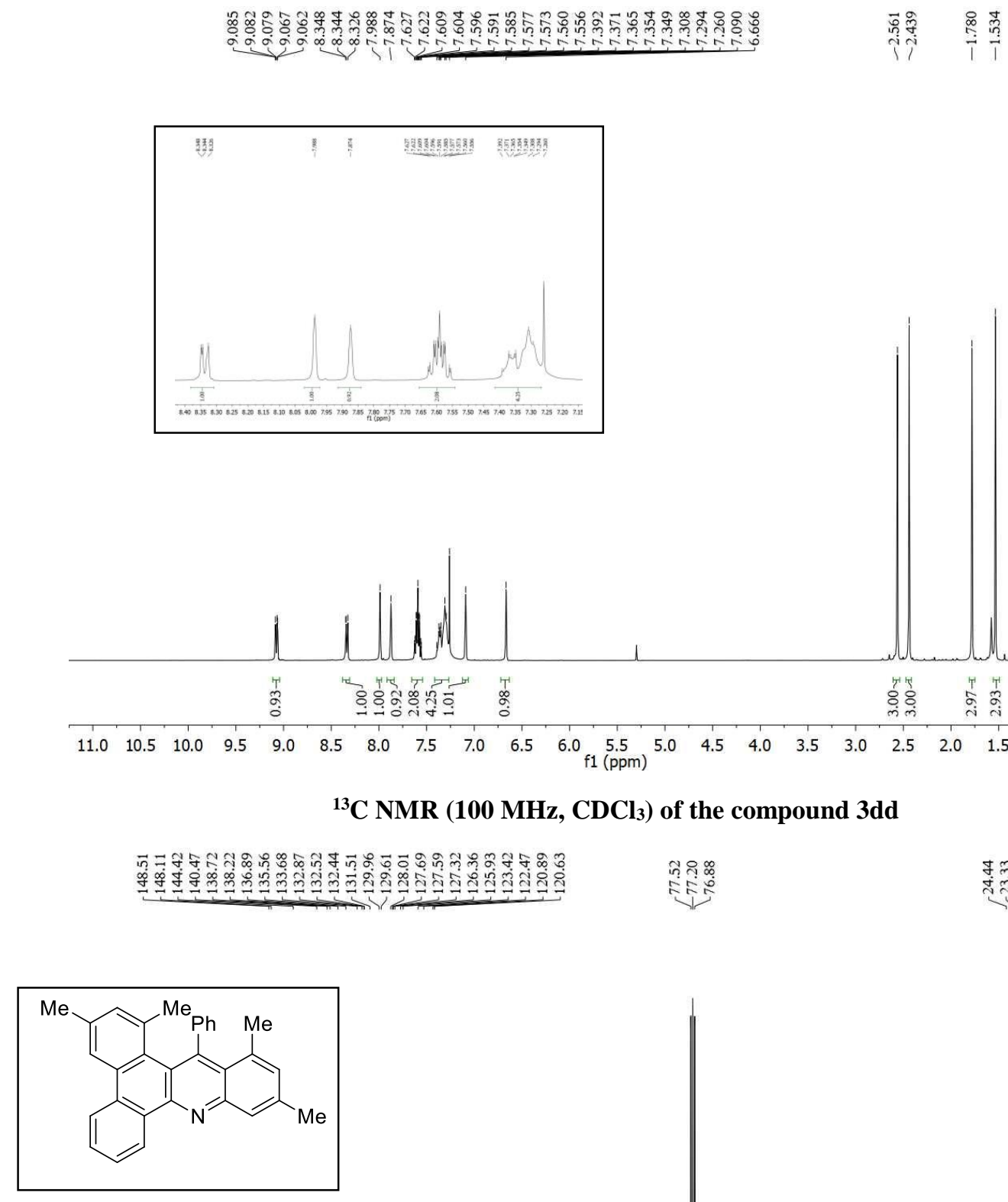

${ }^{13} \mathrm{C}$ NMR (100 MHz, $\left.\mathrm{CDCl}_{3}\right)$ of the compound 3dd

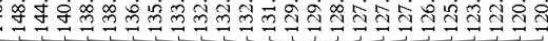
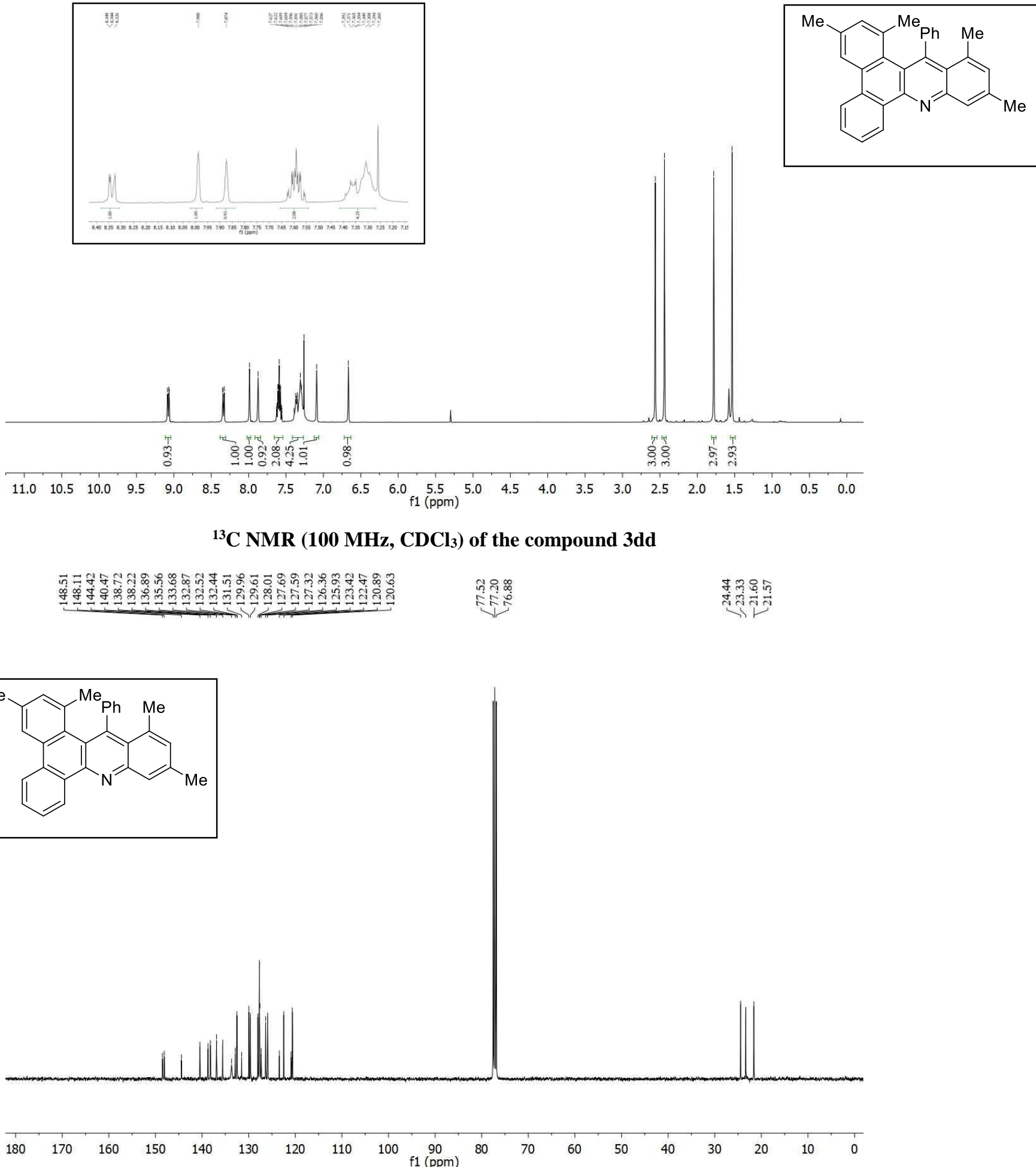
(10) 
${ }^{1} \mathrm{H}$ NMR (400 MHz, $\left.\mathrm{CDCl}_{3}\right)$ of the compound 3cb
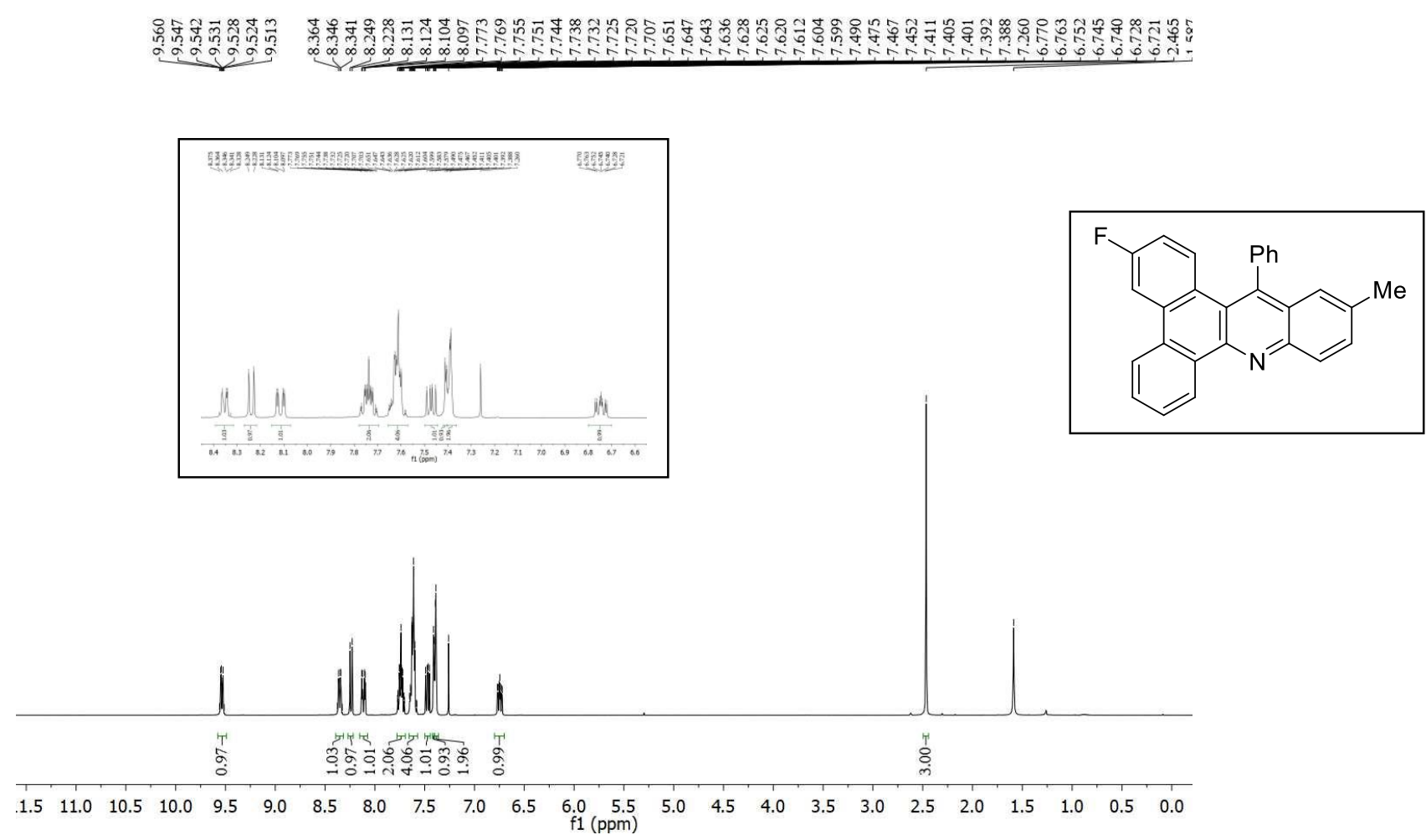

${ }^{13} \mathrm{C}$ NMR (100 $\left.\mathrm{MHz}, \mathrm{CDCl}_{3}\right)$ of the compound 3cb

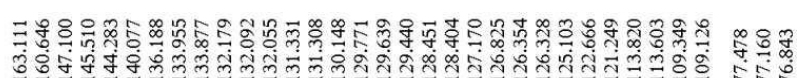

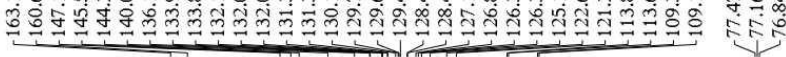
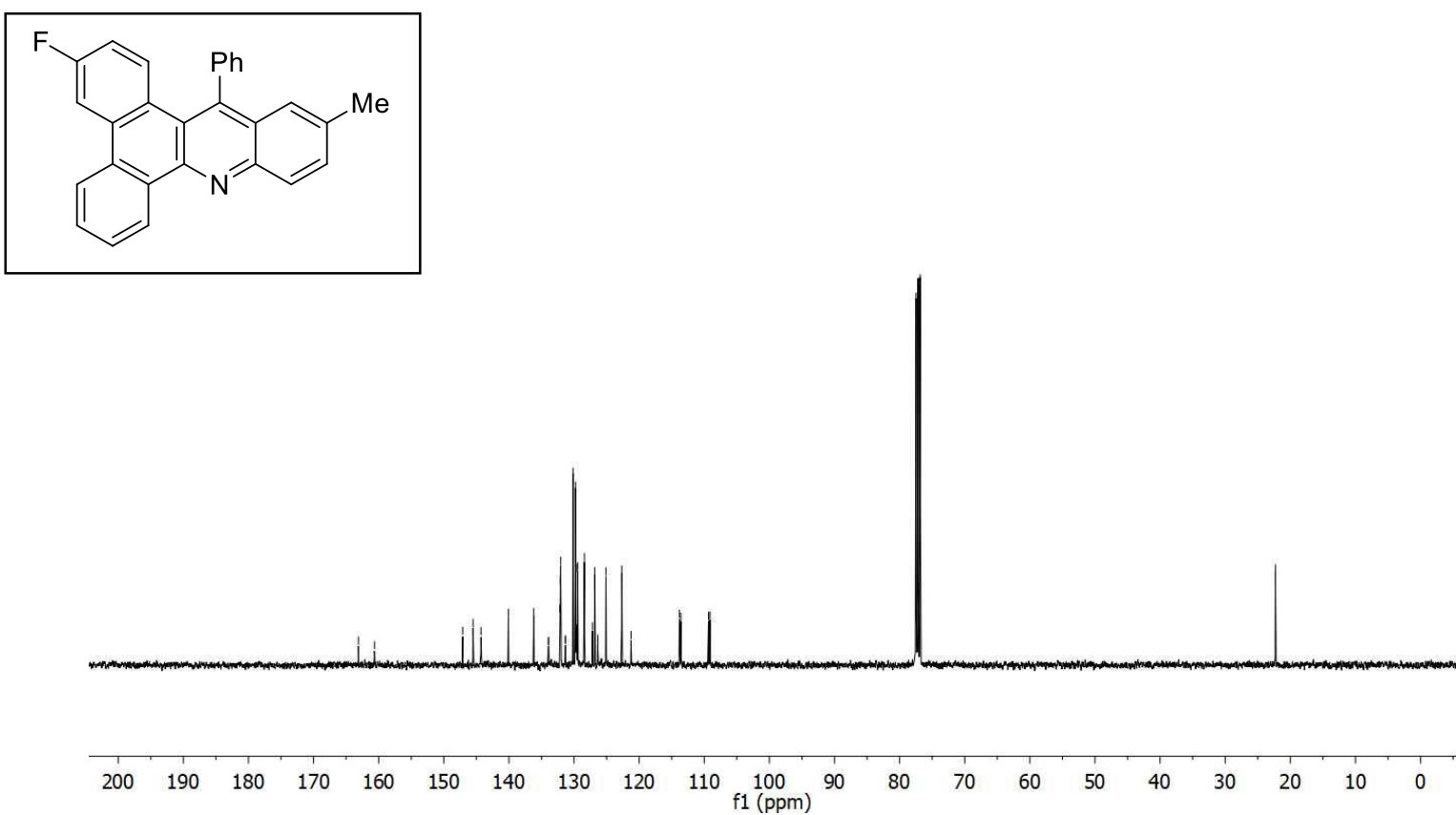
${ }^{1} \mathrm{H}$ NMR (400 MHz, $\left.\mathrm{CDCl}_{3}\right)$ of the compound 3eb

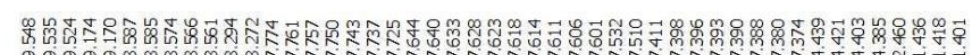

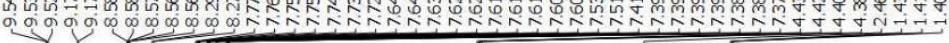
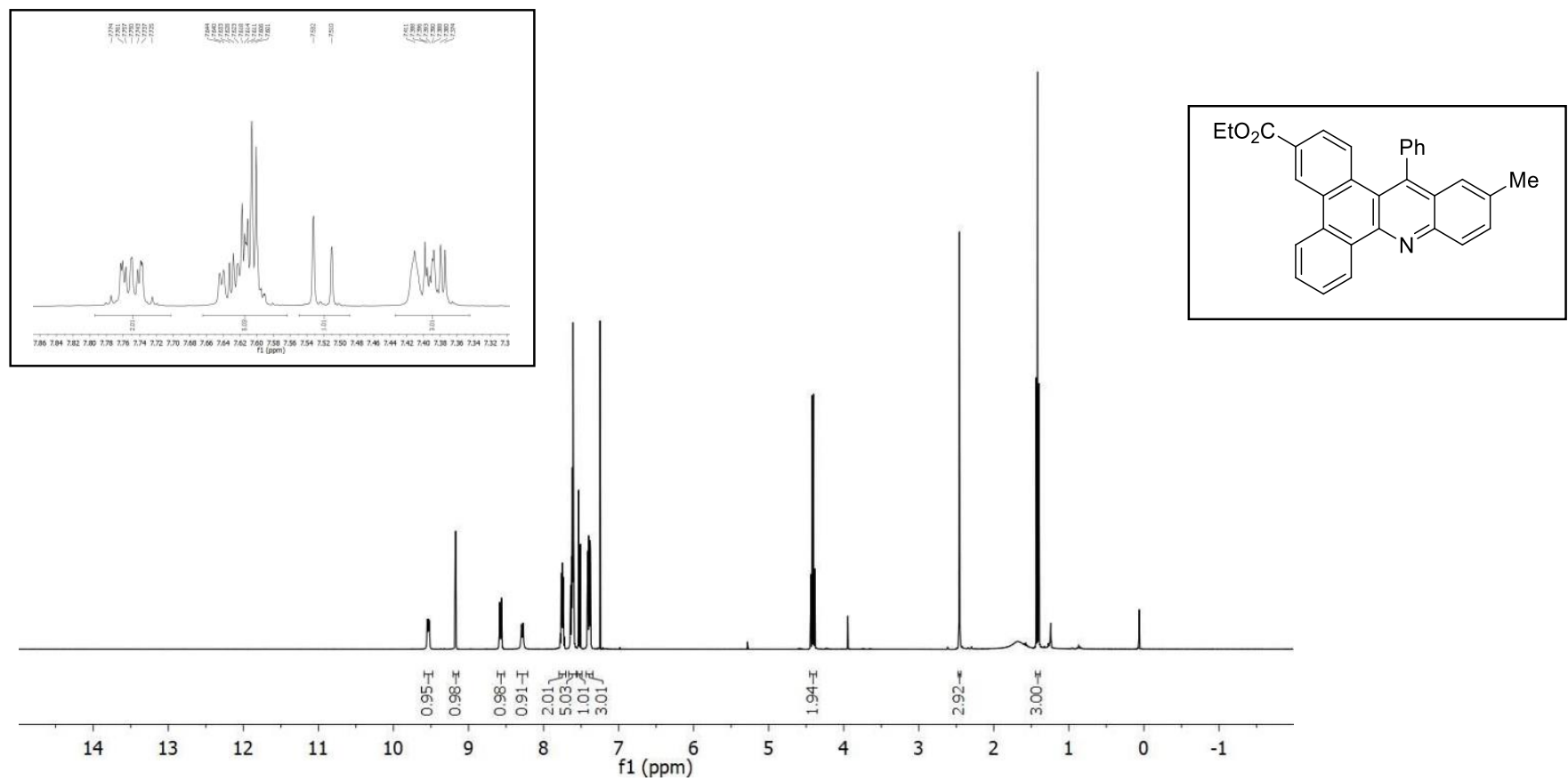

${ }^{13} \mathrm{C}$ NMR (100 MHz, $\mathrm{CDCl}_{3}$ ) of the compound 3eb
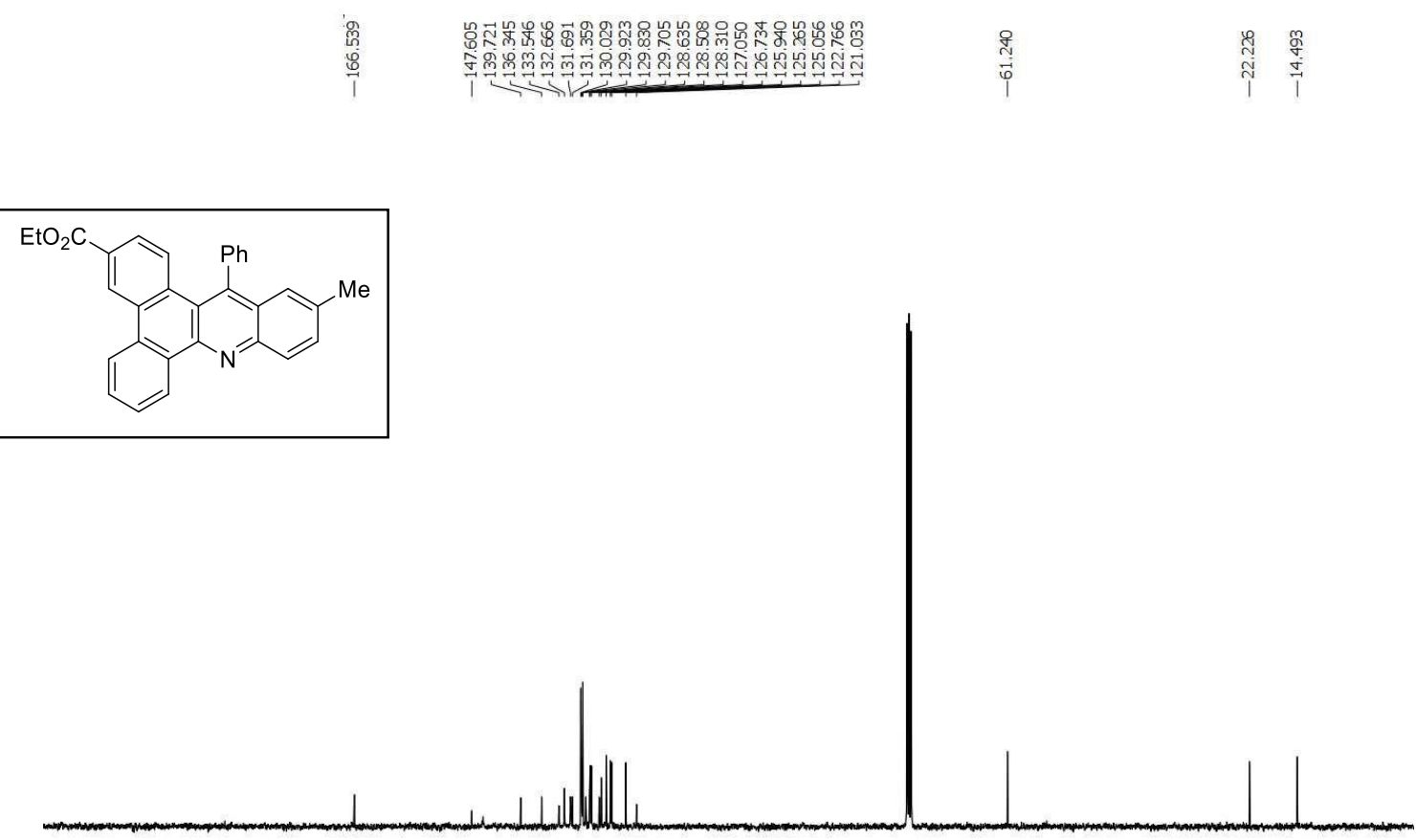

$\begin{array}{llllllllllllllllllllllll}210 & 200 & 190 & 180 & 170 & 160 & 150 & 140 & 130 & 120 & 110 & 100 & 90 & 80 & 70 & 60 & 50 & 40 & 30 & 20 & 10 & 0\end{array}$ 
${ }^{1} \mathrm{H}$ NMR (400 MHz, CDCl 3$)$ of the compound $3 \mathrm{bf}$

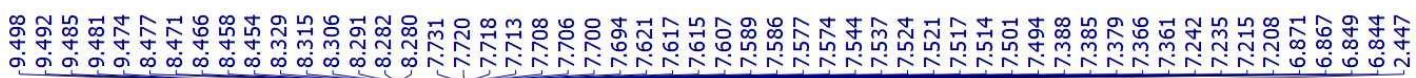
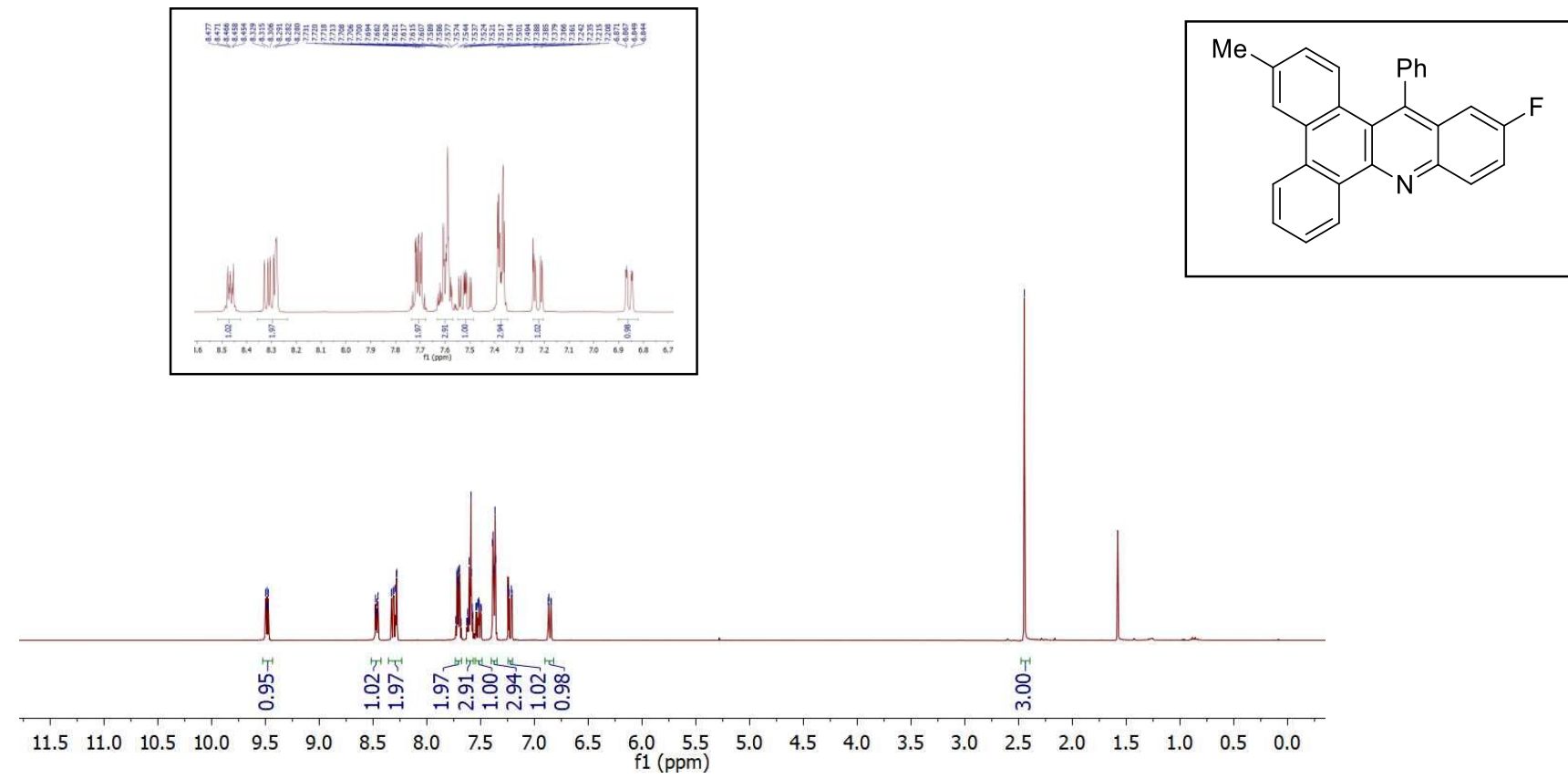

${ }^{13} \mathrm{C}$ NMR (100 $\left.\mathrm{MHz}, \mathrm{CDCl}_{3}\right)$ of the compound $3 \mathrm{bf}$

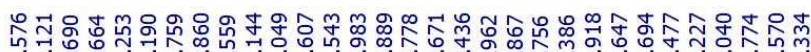

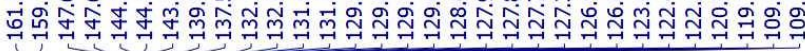
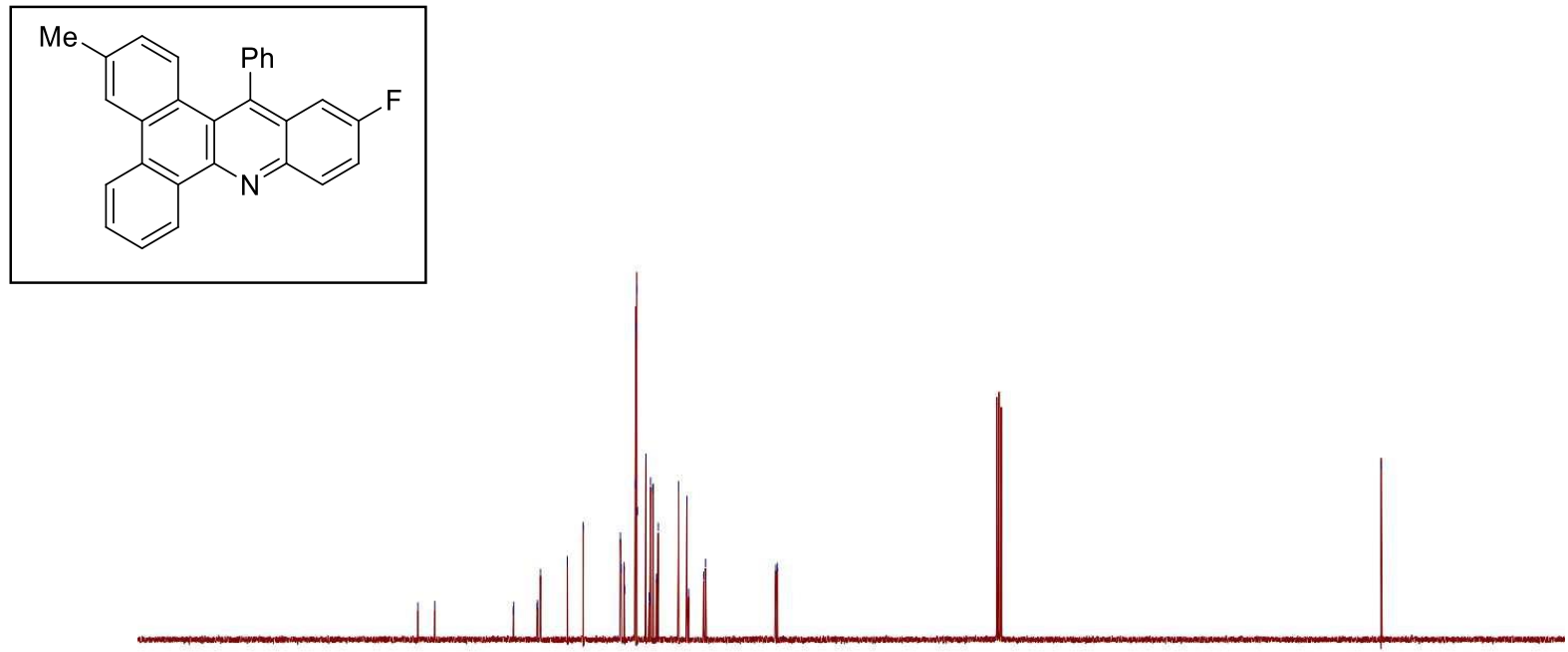

$\begin{array}{lllllllllllllllllll}200 & 190 & 180 & 170 & 160 & 150 & 140 & 130 & 120 & 110 & \begin{array}{c}100 \\ \mathrm{f} 1(\mathrm{ppm})\end{array}\end{array}$ 
${ }^{1} \mathrm{H}$ NMR (400 MHz, $\mathrm{CDCl}_{3}$ ) of the compound 3cg

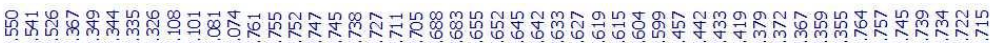

gio 0
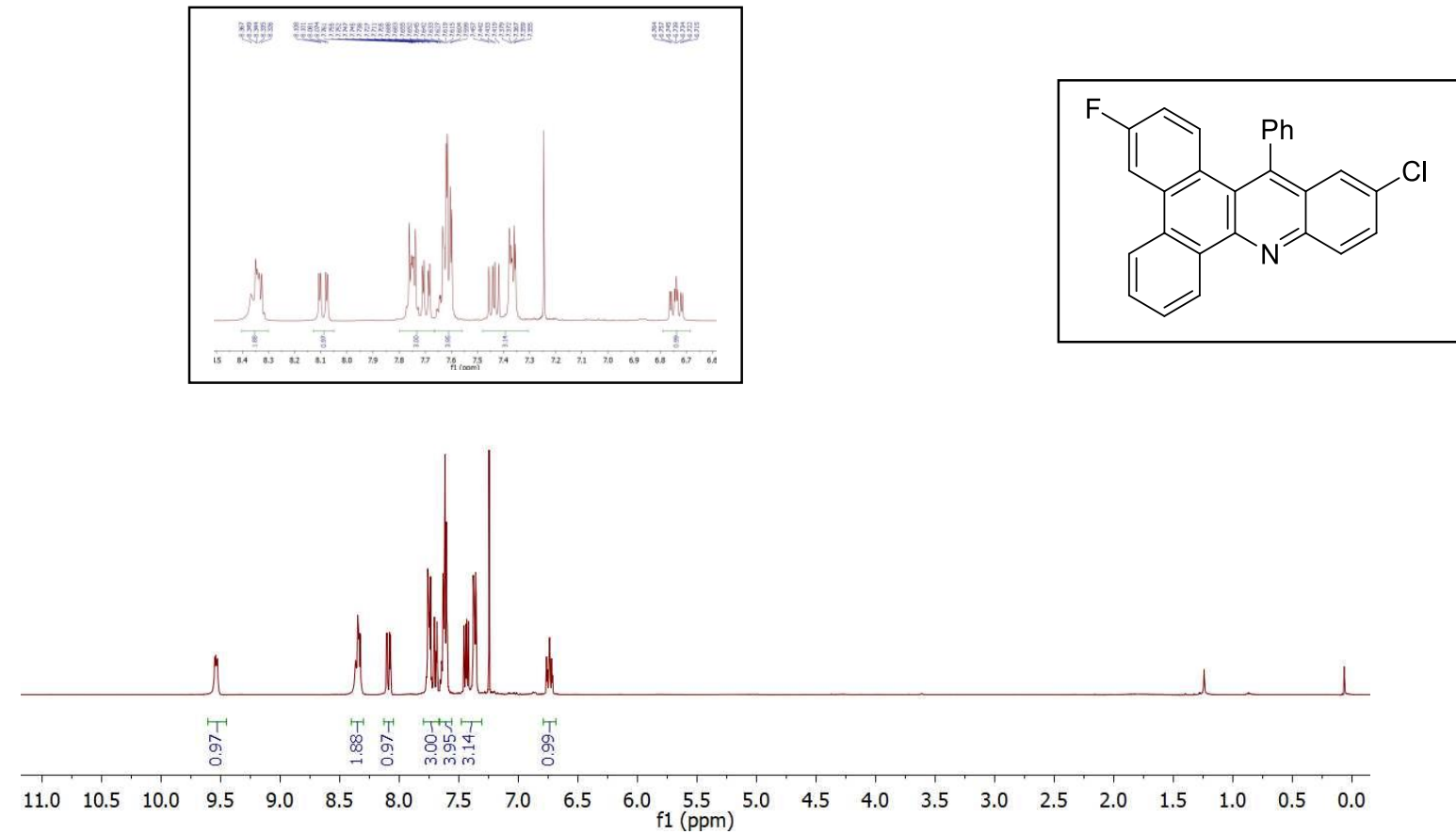

${ }^{13} \mathrm{C}$ NMR (100 $\left.\mathrm{MHz}, \mathrm{CDCl}_{3}\right)$ of the compound $3 \mathrm{cg}$

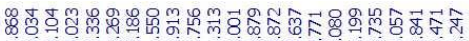

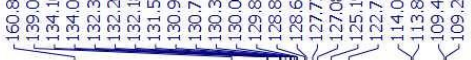

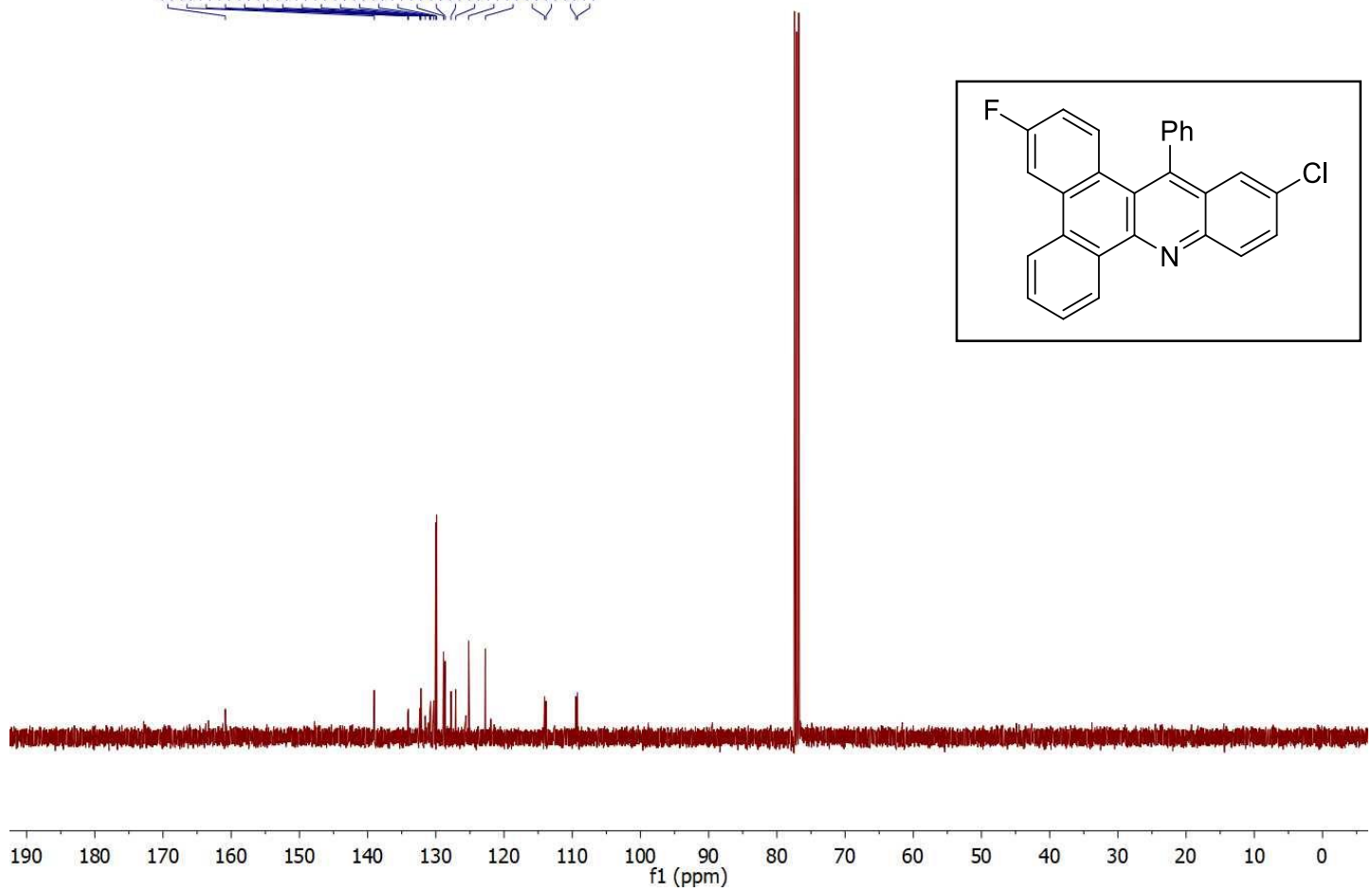


${ }^{1} \mathrm{H}$ NMR (400 MHz, CDCl 3 ) of the compound $3 \mathrm{fb}$

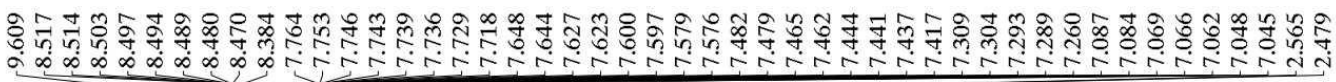

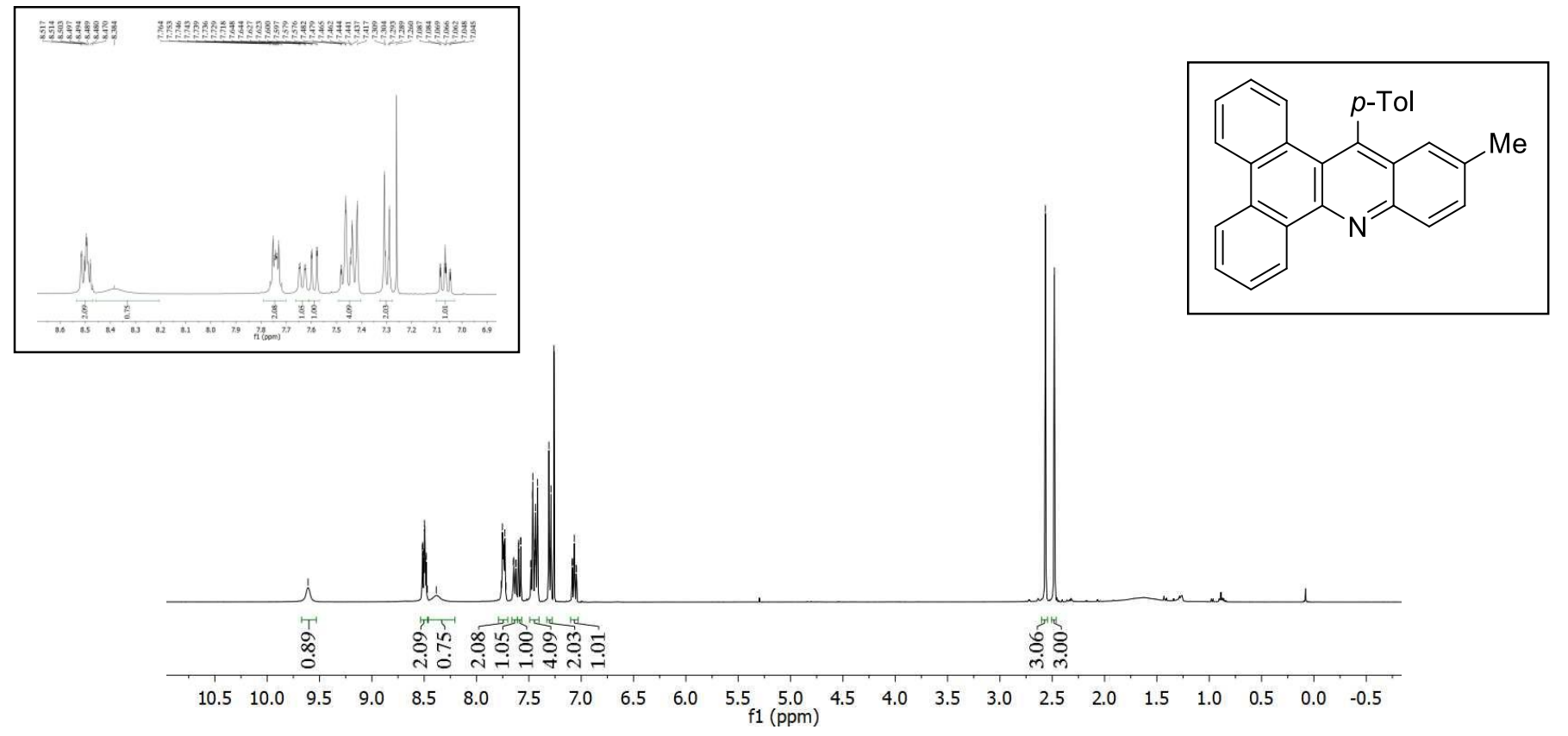

${ }^{13} \mathrm{C}$ NMR (100 $\left.\mathrm{MHz}, \mathrm{CDCl}_{3}\right)$ of the compound $3 \mathrm{fb}$

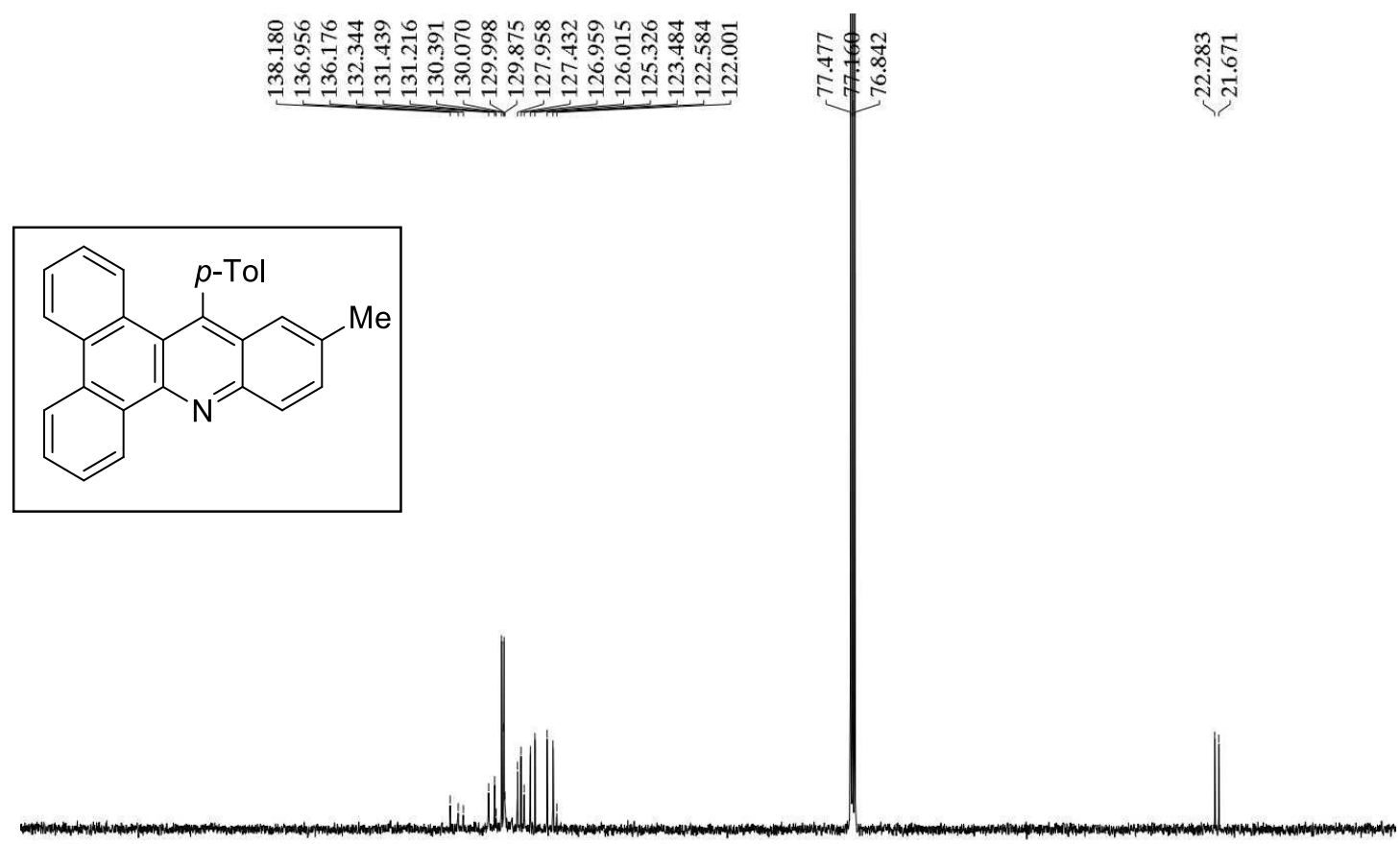

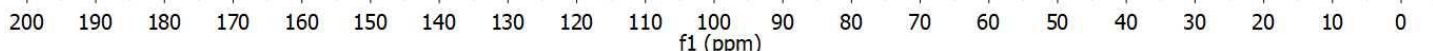


${ }^{1} \mathrm{H}$ NMR (400 MHz, $\left.\mathrm{CDCl}_{3}\right)$ of the compound 3ga

$\underbrace{2}$
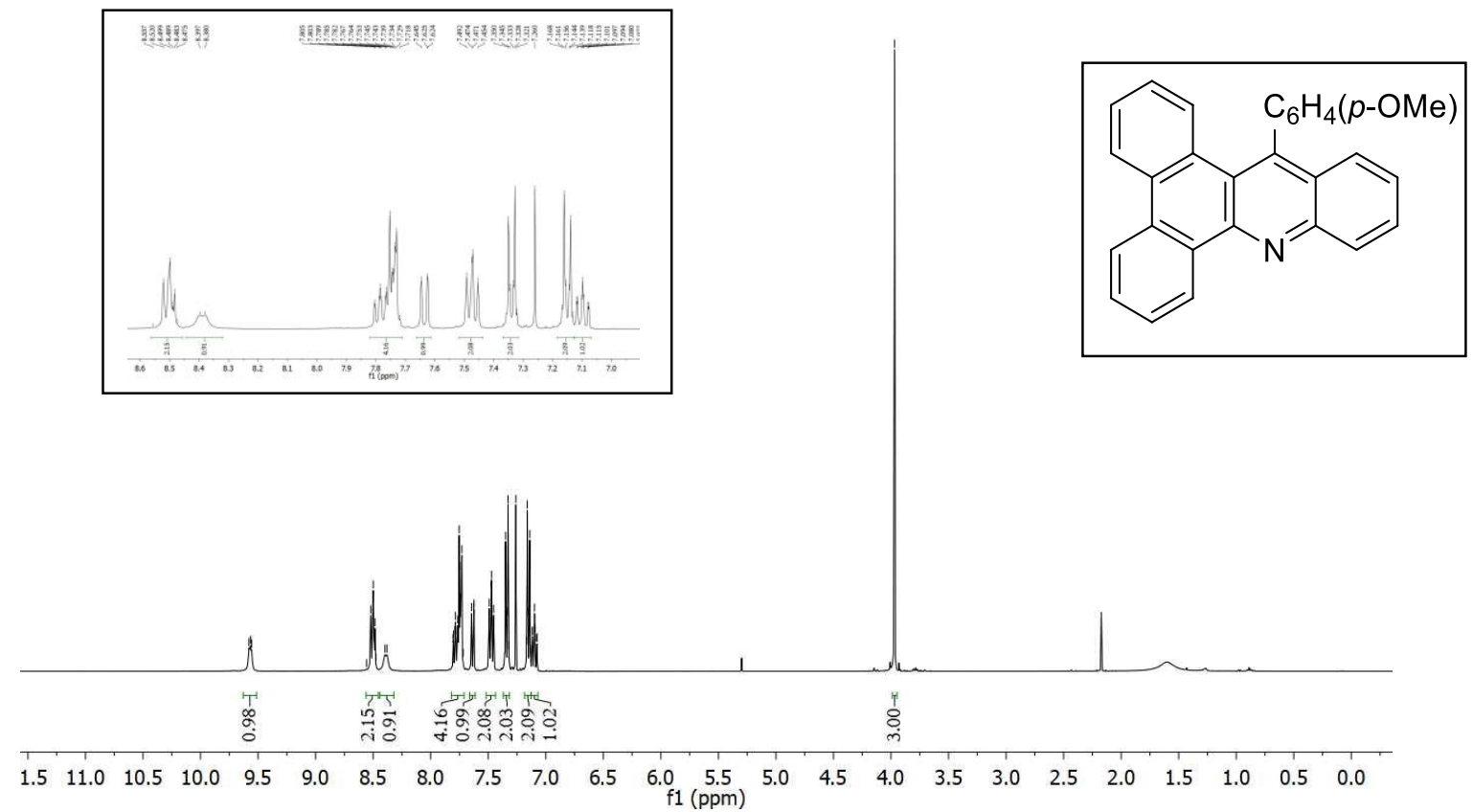

${ }^{13} \mathrm{C}$ NMR (100 $\mathrm{MHz}, \mathrm{CDCl}_{3}$ ) of the compound 3ga

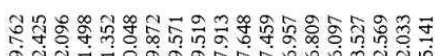

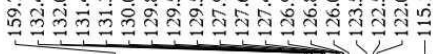

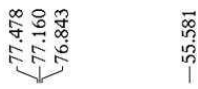
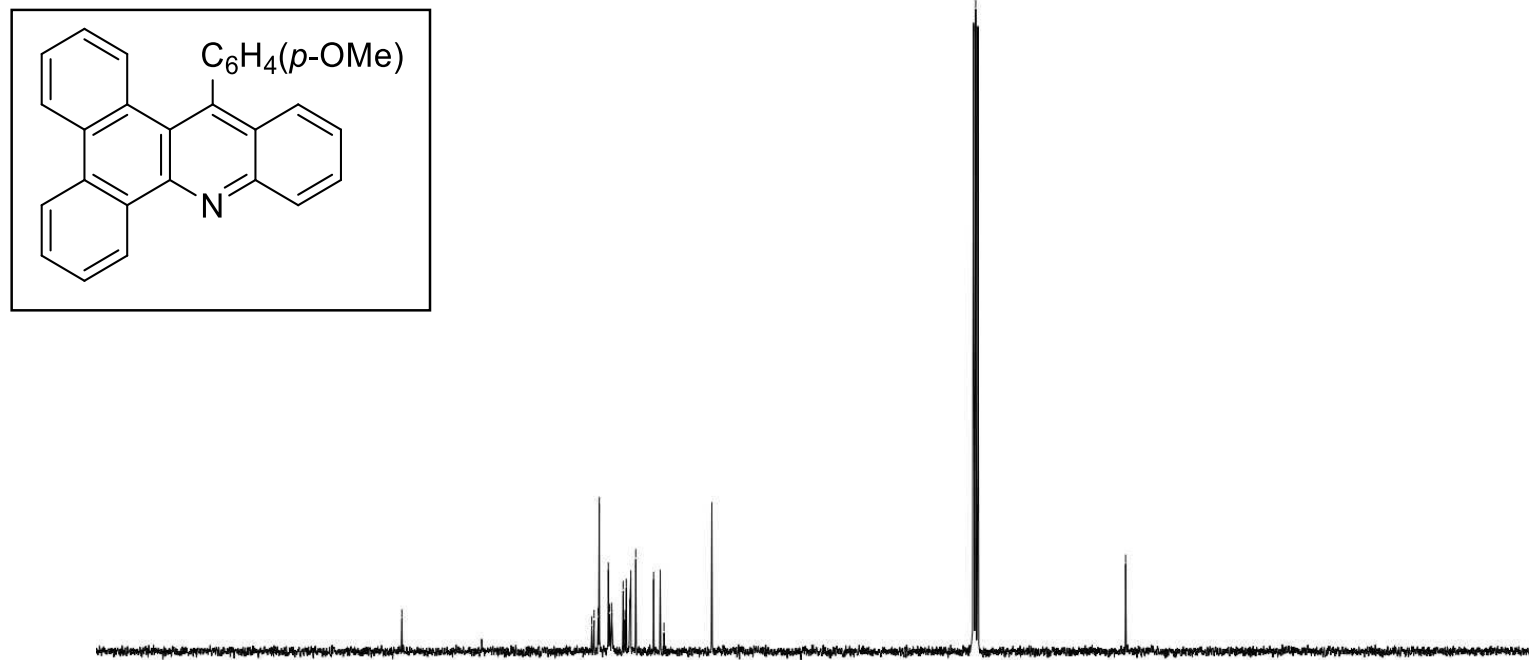

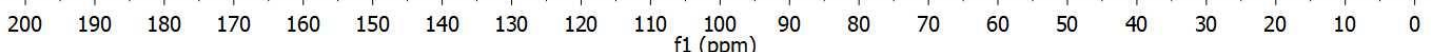


${ }^{1} \mathrm{H}$ NMR (400 $\left.\mathrm{MHz}, \mathrm{CDCl}_{3}\right)$ of the compound $5 \mathrm{fa}$
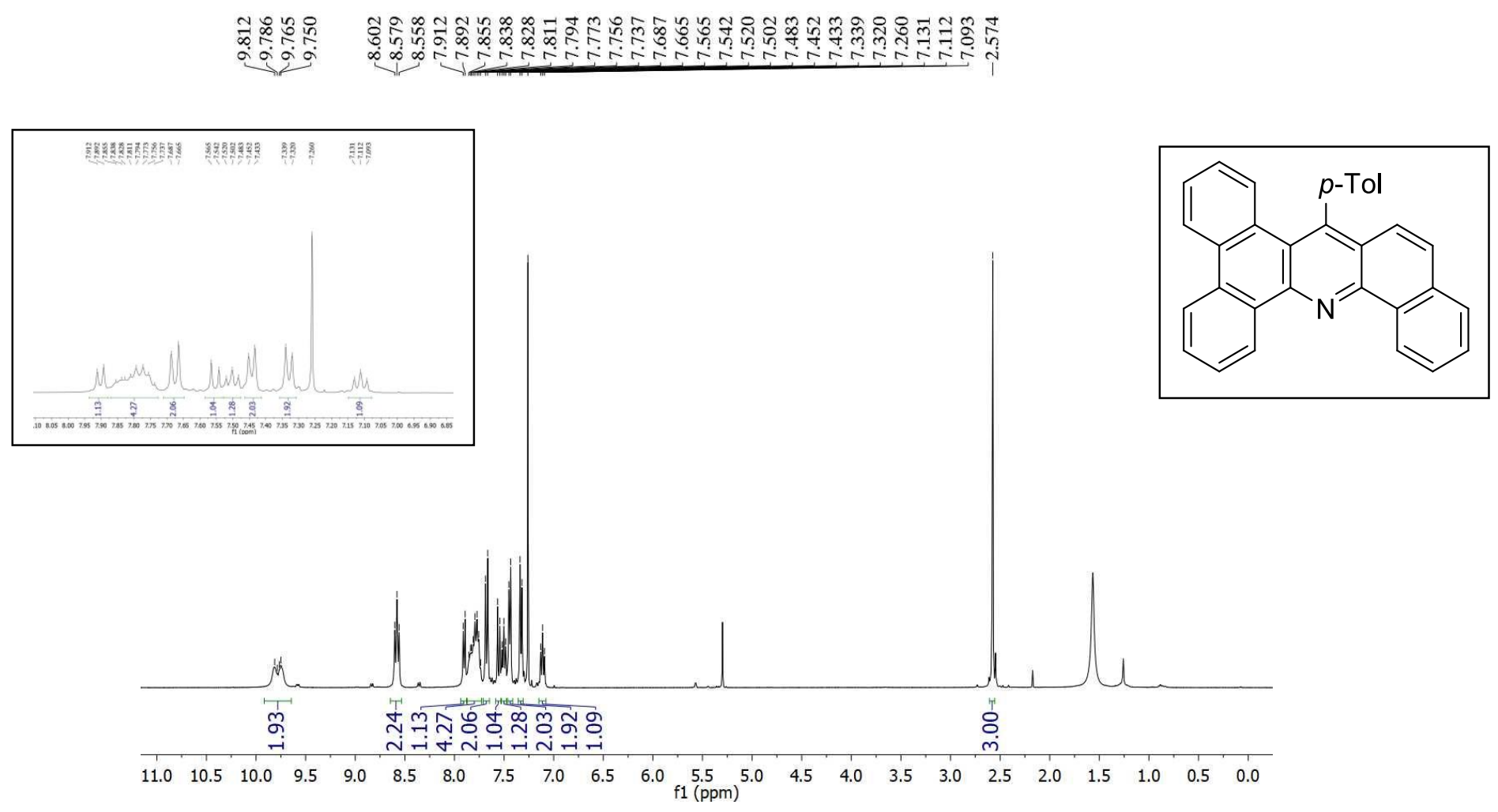

${ }^{13} \mathrm{C}$ NMR (100 MHz, $\left.\mathrm{CDCl}_{3}\right)$ of the compound $5 \mathrm{fa}$

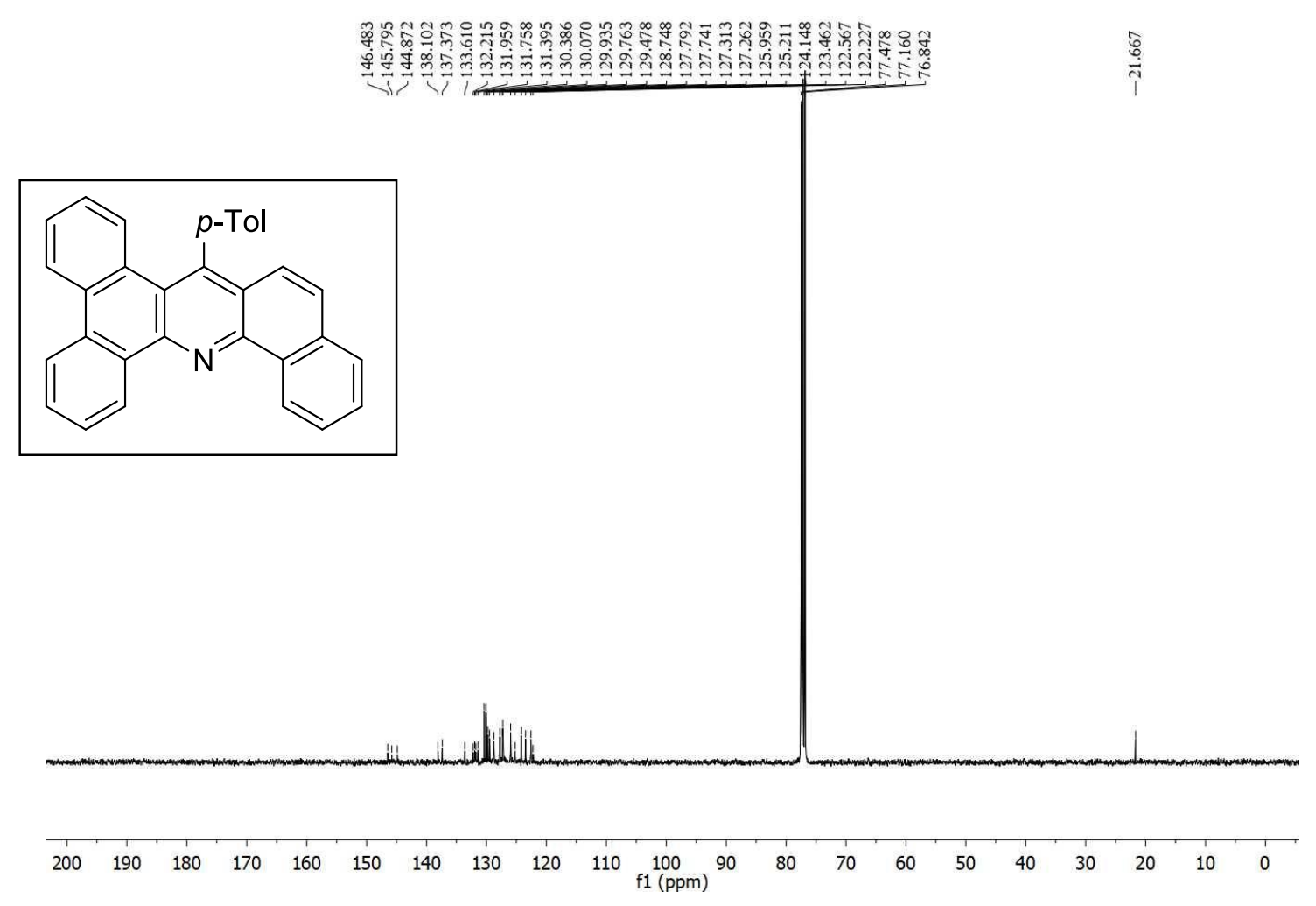

